\title{
Integration of Lupinus angustifolius L. (narrow-leafed lupin) genome maps and comparative mapping within legumes
}

\author{
Katarzyna Wyrwa • Michal Książkiewicz • Anna Szczepaniak • \\ Karolina Susek • Jan Podkowiński • Barbara Naganowska
}

Received: 7 March 2016 /Revised: 14 April 2016/Accepted: 24 April 2016/Published online: 11 May 2016

(C) The Author(s) 2016. This article is published with open access at Springerlink.com

\begin{abstract}
Narrow-leafed lupin (Lupinus angustifolius L.) has recently been considered a reference genome for the Lupinus genus. In the present work, genetic and cytogenetic maps of L. angustifolius were supplemented with 30 new molecular markers representing lupin genome regions, harboring genes involved in nitrogen fixation during the symbiotic interaction of legumes and soil bacteria (Rhizobiaceae). Our studies resulted in the precise localization of bacterial artificial chromosomes (BACs) carrying sequence variants for early nodulin 40 , nodulin 26 , nodulin 45 , aspartate aminotransferase $\mathrm{P} 2$, asparagine synthetase, cytosolic glutamine synthetase, and phosphoenolpyruvate carboxylase. Together with previously mapped chromosomes, the integrated L. angustifolius map encompasses 73 chromosome markers, including 5S ribosomal DNA (rDNA) and 45S rDNA, and anchors 20 L. angustifolius linkage groups to corresponding chromosomes. Chromosomal identification using BAC fluorescence in situ
\end{abstract}

Responsible editor: Hans de Jong

Electronic supplementary material The online version of this article (doi:10.1007/s10577-016-9526-8) contains supplementary material, which is available to authorized users.

K. Wyrwa $(\bowtie) \cdot$ M. Książkiewicz • A. Szczepaniak •

K. Susek $\cdot$ B. Naganowska

Institute of Plant Genetics of the Polish Academy of Sciences,

Strzeszyńska 34, Poznań 60-479, Poland

e-mail: kwyr@igr.poznan.pl

J. Podkowiński

Institute of Bioorganic Chemistry of the Polish Academy of

Sciences, Z. Noskowskiego 12/14, Poznań 61-704, Poland hybridization identified two BAC clones as narrow-leafed lupin centromere-specific markers, which served as templates for preliminary studies of centromere composition within the genus. Bioinformatic analysis of these two BACs revealed that centromeric/pericentromeric regions of narrow-leafed lupin chromosomes consisted of simple sequence repeats ordered into tandem repeats containing the trinucleotide and pentanucleotide simple sequence repeats AGG and GATAC, structured into long arrays. Moreover, cross-genus microsynteny analysis revealed syntenic patterns of 31 single-locus BAC clones among several legume species. The gene and chromosome level findings provide evidence of ancient duplication events that must have occurred very early in the divergence of papilionoid lineages. This work provides a strong foundation for future comparative mapping among legumes and may facilitate understanding of mechanisms involved in shaping legume chromosomes.

Keywords Lupinus angustifolius · chromosome markers $\cdot$ integrated map $\cdot$ rDNA $\cdot$ centromeres $\cdot$ synteny
Abbreviations
AAT-P2 Aspartate aminotransferase P2
Ad Arachis duranensis chromosome
Ai Arachis ipaensis chromosome
$A S$ Asparagine synthetase
AS-PCR Allele-specific PCR
BAC Bacterial artificial chromosome
BAC-FISH Fluorescence in situ hybridization with BACs as molecular probes
BES BAC-end sequence 


$\begin{array}{ll}\text { Ca } & \text { Cicer arietinum chromosome } \\ \text { CAPS } & \begin{array}{l}\text { Cleaved Amplified } \\ \text { Polymorphic Sequence }\end{array} \\ \text { Cc } & \text { Cajanus cajan chromosome } \\ \text { ENOD40 } & \text { Early nodulin } 40 \\ \text { FISH } & \text { Fluorescence in situ hybridization } \\ \text { Gm } & \text { Glycine max chromosome } \\ \text { GS } & \text { Glutamine synthetase } \\ \text { GS1 } & \text { Cytosolic glutamine synthetase } \\ \text { Lang } & \text { Narrow-leafed lupin chromosome } \\ \text { LINE } & \text { Long interspersed nuclear elements } \\ \text { Lj } & \text { Lotus japonicus chromosome } \\ \text { LOD } & \text { Logarithm of the odds } \\ \text { Mt } & \text { Medicago truncatula chromosome } \\ \text { NLL } & \text { Narrow-leafed lupin linkage group } \\ \text { NOD26 } & \text { Nodulin } 26 \\ \text { NOD45 } & \text { Nodulin } 45 \\ \text { PEPC } & \text { Phosphoenolpyruvate carboxylase } \\ \text { Pv } & \text { Phaseolus vulgaris chromosome } \\ \text { SNPs } & \text { Single-nucleotide polymorphisms } \\ \text { SSR } & \text { Single sequence repeat } \\ \text { Vr } & \text { Vigna radiata chromosome }\end{array}$

\section{Introduction}

Plant nuclear genomes are organized into chromosomes that facilitate genome investigation (Heslop-Harrison and Schwarzacher 2011). Despite the increasing amounts of genetic, genomic, and transcriptomic data that are now available, little is known about plant chromosomal organization and evolution. Studies of entire sets of chromosomes (karyotype) using cytogenetic approaches have been important in identifying chromosome number, size, and morphology. In addition, cytogenetics is a useful tool for the distinction or characterization of species and inference of their evolution and relationships (Kato et al. 2005; Iovene et al. 2008; Figueroa and Bass 2010). Karyotype analyses, especially in species with symmetric karyotype and many chromosomes, allow the genome structure to be tracked (Paterson et al. 2000; Young et al. 2012; Dolezel et al. 2014). In species with well-established genomic resources for chromosome markers, the availability of whole-genome sequences has contributed significantly to the construction of chromosomal maps and the further assignment of the markers to physical/linkage groups (Sato et al. 2007). However, in species with numerous small and uniform chromosomes, genomic studies are still a challenge, especially when a completely assembled reference genome sequence is not yet available.

Fluorescence in situ hybridization (FISH), especially with large-insert bacterial artificial chromosomes (BACs) as molecular probes (BAC-FISH), has contributed greatly to plant genome analyses at the chromosomal level. FISH techniques have been widely used to generate landmarks for plant mitotic (Hasterok et al. 2006; Lamb et al. 2007; Hřibová et al. 2008) and meiotic (Lysak et al. 2001; Idziak et al. 2011) chromosomes. These cytogenetic markers are essential not only to distinguish particular chromosomes but also for assignment of genetic and chromosomal maps (Ellis and Poyser 2002; Ohmido et al. 2010) and alignment of genome sequence assemblies to chromosomes (Sun et al. 2013; Shearer et al. 2014). BAC-FISH has been applied for chromosome characterization and integrative mapping in many species including Brassica oleracea, Phaseolus lunatus, Phaseolus vulgaris, Sorghum bicolor, Oryza sativa, Arabidopsis thaliana, and Solanum esculentum (Jiang et al. 1995; Islam-Faridi et al. 2002; Kim et al. 2002; Koornneef et al. 2003; Howell et al. 2005; Koo et al. 2008; Bonifacio et al. 2012). The integration of B. oleracea cytogenetic and genetic linkage maps was achieved with $22 \mathrm{BAC}$ probes representing 19 loci (Howell et al. 2002). FISH also allowed the simultaneous identification of all 10 sorghum chromosomes using $17 \mathrm{BAC}$ probes (Kim et al. 2002). Similar approaches have been applied for karyotype analyses of legumes, such as common bean (Pedrosa-Harand et al. 2009; Fonseca et al. 2010) and soybean (Findley et al. 2010). Genetically anchored BAC clones were used both to identify individual chromosomes in metaphase spreads and to establish a complete FISH-based karyotyping cocktail that permitted simultaneous identification of all 20 soybean chromosome pairs (Findley et al. 2010). Genome maps that associate all the chromosomes to corresponding linkage groups have been constructed for a number of plant species (Feng et al. 2013) including Medicago truncatula (Schnabel et al. 2003), Lotus japonicus (Ohmido et al. 2010), and P. vulgaris (Fonseca et al. 2010).

An important step in karyotype analyses is determining the position and composition of the centromere region. Although the prominence of the role of centromeres during cell divisions is known, they are often overlooked during whole-genome studies at both the 
sequence and chromosomal levels. Centromere sequence organization studies have been performed to complement the understanding of the structure of higher plant genomes as well as to decipher their evolution dynamics (Neumann et al. 2015). Analyses of sequence data revealed that plant centromeres are rich in various types of repetitive DNA (He et al. 2015). Despite the conserved function of centromeres in all eukaryotic cells, large size variations and sequence divergence have been reported, even between closely related species (Melters et al. 2013; Neumann et al. 2015). Flowering plant centromeres in an individual genome are generally composed of the same types of DNA components, mainly large arrays of tandem satellite repeats and retrotransposons. A common characteristic of centromeric satellite repeats is their rapid divergence (Ma et al. 2007a; Melters et al. 2013), and polymorphisms have been found between individual chromosomes in the same genome, involving nucleotide sequence and copy numbers of repeats, as well as their spacing, order, and orientation (Yi et al. 2013). Whole-genome sequence annotations have revealed that the centromere composition in legumes also varies from one species to another (Cannon et al. 2009).

The legume family (Fabaceae) comprises approximately 19,500 species distributed in diverse ecological and geographical habitats (Lewis 2005). Extensive studies of a hallmark trait of $88 \%$ of legume species, namely, their ability to develop root nodules and to fix atmospheric nitrogen in symbiosis with compatible Rhizobia, have been performed to better understand this process and for future improvement of legume crops. Genes involved in signal exchange between symbionts have been identified, primarily through genetic analysis and analytical chemistry. Transcriptomic analysis of complementary DNA (cDNA) libraries of Glycine max and $M$. truncatula suggested that 6555 genes may be involved in Fabaceae-Rhizobiaceae symbiosis (Brechenmacher et al. 2008). Among them, many transcription factors (Fedorova et al. 2002) and genes encoding early nodulin 40 (ENOD40) (Compaan et al. 2001), nodulin 26 (NOD26) (Wallace et al. 2006), nodulin 45 (NOD45) (Macknight et al. 1995), aspartate aminotransferase (AAT) (Griffith and Vance 1989), asparagine synthetase (AS) (Gaufichon et al. 2010), glutamine synthetase (GS) (Datta et al. 1991), and phosphoenolpyruvate carboxylase (PEPC) (Schuller et al. 1990) were predicted to play crucial roles during nitrogen fixation. The genus Lupinus, as a representative of legume species, exhibits many distinctive Fabaceae features, including the ability to fix atmospheric nitrogen by symbiosis with soil nitrogen-fixing bacteria (Graham and Vance 2003). Lupinus angustifolius (narrow-leafed lupin) is the most studied species within the genus, and it now became a reference organism in legume studies (Książkiewicz et al. 2015). The genetic toolbox of L. angustifolius encompasses molecular markers, transcriptome data, and a draft genome sequence, and the generation of thousands of molecular markers has facilitated the construction of genetic maps (Boersma et al. 2005; Kasprzak et al. 2006; Nelson et al. 2010; Gao et al. 2011; Kroc et al. 2014; Foley et al. 2015; Yang et al. 2015; Kamphuis et al. 2015). Cytogenetic investigation of the L. angustifolius genome has been hampered by the high number of small and similar chromosomes $(2 n=40)$; nevertheless, some progress has been made. Analysis of the distribution of $5 \mathrm{~S}$ and 45S ribosomal DNA (rDNA) loci allowed the identification of two pairs of chromosome markers for L. angustifolius (Naganowska and Zielinska 2002). A breakthrough in chromosomal studies in lupin was achieved using clones from a BAC library of the L. angustifolius nuclear genome for BAC-FISH (Leśniewska et al. 2011). Moreover, FISH-based mapping combined with genetic marker development resulted in the assignment of the first three linkage groups to corresponding chromosomes of L. angustifolius (Leśniewska et al. 2011), and BAC-FISH has been used to associate additional 10 linkage groups with chromosomes (Książkiewicz et al. 2013, 2015; Przysiecka et al. 2015). We also performed a complex L. angustifolius genome survey by combining the genetic and cytogenetic characterization of BAC clones, followed by sequence annotation and comparative studies of nine legume plants, which justified the conclusion that the genome regions studied had undergone whole-genome duplication (Książkiewicz et al. 2015).

Here, we describe the complete assignment of narrow-leafed lupin chromosomes to linkage groups on the most recent genetic map (Kamphuis et al. 2015). We identified, sequenced, and annotated two narrow-leafed lupin BAC clones as centromerespecific markers that may serve as a unique template for further studies of centromere composition within the Lupinus genus. We also present the comprehensive characterization of $L$. angustifolius genome regions that correspond to nine single-locus BAC clones and evidence their cross-genus microsynteny. 


\section{Materials and methods}

Plant material

Seeds of $L$. angustifolius cv. Sonet $(2 \mathrm{n}=40)$, L. albus $\mathrm{cv}$. Boros $(2 \mathrm{n}=50)$, and L. luteus cv. Mister $(2 \mathrm{n}=52)$ were obtained from the Polish Lupin GenBank in the Breeding Station Wiatrowo (Poznan Plant Breeders Ltd., Poland). Seeds of $L$. angustifolius mapping population were provided by Dr. Hua'an Yang (Department of Agriculture and Food Western Australia). Seeds of Triticum aestivum and Nicotiana tabacum were kindly provided by Dr. Michał Kwiatek (Department of Genomics, Institute of Plant Genetics PAS) and Dr. Tomasz Pniewski (Department of Biotechnology, IPG PAS), respectively.

\section{Screening of BAC library}

A set of BAC clones was selected by screening the L. angustifolius cv. Sonet nuclear genome BAC library (Kasprzak et al. 2006) with sequence-specific probes, targeting ENOD40, NOD26, NOD45, and aspartate aminotransferase P2 (AAT-P2) genes. Target genes were chosen based on their involvement in pathway leading to symbiotic interaction of legume plants with nitrogenfixing bacteria. Degenerated primers were anchored in gene sequences and designed using the following templates: L. luteus ENOD40 (accession number AF352375), G. $\max$ NOD26 (L12257), L. angustifolius NOD45 (L12388), and L. angustifolius AAT-P2 (L29258) (Online resource 1). Probes were generated using PCR with $L$. angustifolius genomic DNA as a template (25 ng DNA), Taq polymerase (Novazym, Poznan, Poland) supplied with $1 \times$ PCR buffer and $2.5 \mathrm{mM} \mathrm{Mg}^{2+}, 0.16 \mathrm{mM}$ dNTP, $0.25 \mu \mathrm{M}$ of each primer, and deionized water up to $20 \mu \mathrm{L}$. The PCR amplification involved initial denaturation $\left(94{ }^{\circ} \mathrm{C}, 5 \mathrm{~min}\right)$; then 40 cycles consisting of three steps, denaturation $\left(94{ }^{\circ} \mathrm{C}, 30 \mathrm{~s}\right)$, annealing $\left(54-58{ }^{\circ} \mathrm{C}\right.$, $40 \mathrm{~s}$ ) (Online resource 1$)$, elongation $\left(72{ }^{\circ} \mathrm{C}, 55 \mathrm{~s}\right)$; and followed by final elongation $\left(72^{\circ} \mathrm{C}, 5 \mathrm{~min}\right)$. PCR products were purified with QIAquick PCR Purification Kit (Qiagen, Hilden, Germany) and sequenced. Probes were radioactively labeled by random priming with HexaLabel DNA Labeling Kit (Fermentas Waltham, MA, USA) with $50 \mu \mathrm{Ci}[\alpha-32 \mathrm{P}]-\mathrm{dCTP}$. The hybridization of probes with the nuclear genome BAC library and verification of positive signals were carried out as previously described by Książkiewicz et al. (2013). Moreover, in order to integrate genetic and cytogenetic maps of all narrow-leafed lupin chromosomes, the research material was supplemented with 13 clones selected from other project concerning analysis of cytosolic glutamine synthetase (GS1), PEPC, and $A S$ genes (Wyrwa, unpublished), genes encoding enzymes indispensable in active symbiosome during nitrogen fixation process.

\section{BAC-end and BAC insert sequencing}

Selected BAC clones were isolated with PhasePrep BAC DNA Kit (Sigma Aldrich, St. Louis, USA) and subjected to BAC-end sequencing on the ABI PRISM 3130 XL Genetic Analyzer (Applied Biosystems, Foster City, USA) using the following pIndigoBAC5 sequencing primers:

\section{3'-GGATGTGCTGCAAGGCGATTAAGTTGG, 5'-CTCGTATGTTGTGTGGAATTGTGAGC.}

BAC-end sequences (BESs) were analyzed and manually edited with Chromas Lite software (Technylesium, South Brisbane, Australia).

The whole-insert sequencing was performed by Miseq platform (Illumina, San Diego, USA) in pairedend $2 \times 250$-bp approach (Genomed, Warsaw, Poland). BAC clone sequence assembly was performed with the use of CLCGenomicWorkbench (v7.0.4) software under default parameters (automatic word size, yes; automatic bubble size, yes; minimum contig length, 500; auto-detect paired distances, yes; perform scaffolding, yes; map reads back to contigs, yes; mismatch cost, 2; insertion cost, 3; deletion cost, 3; length fraction, 0.5 ; similarity fraction, 0.8 ; update contigs, yes).

Functional annotation of BAC-end and whole-BAC sequences

Obtained sequence data were functionally annotated using nucleotide and protein BLAST algorithms (NCBI, http://www.ncbi.nlm.nih.gov/) in order to identify genes (databases DNA and protein sequences from the EMBL Nucleotide Sequence Database, GenBank, DNA Database of Japan, RCSB Protein Data Bank, SwissProt, Protein Information Resource, and Protein Research Foundation) as well as repetitive sequences (databases RepBase, TIGR, and MIPS Plant Repeats Collections) (Ouyang and Buell 2004; Spannagl et al. 2007). The BLAST algorithm was optimized for highly 
similar sequences (e-value cutoff, 1e-10; word size, 28; match/mismatch scores, 1/-2; and gap costs, linear). The following sequence repositories were used with particular attention: L. luteus, http://www.cgna.cl/ lupinus (project PRJNA170318, archive SRX159101); L. albus, http://comparative-legumes.org (gene index LAGI 1.0); and L. angustifolius (project PRJNA248164, archive GBRP00000000). Gene prediction in BACs was performed using FGENESH (Salamov and Solovyev 2000). Results of functional annotation were subsequently used for gene density (genes/kbp) calculation.

SSR Finder (http://www.fresnostate.edu/ssrfinder/) was used to identify single-sequence repeats (SSRs) with the following parameters: motif length, 2-8; minimum number of repeats, 2; and allowed nucleotide substitution. Repeats differing by reading frames (e.g., AG vs. GA) or reverse-complement reading (e.g., AG vs. CT) were clustered.

Alignment to the draft L. angustifolius genome sequence

BESs were used to screen the collection of L. angustifolius whole-genome shotgun contigs and scaffolds (NCBI Project No. PRJNA179231, assembly version GCA_000338175.1). In the first step, BESs were aligned to the sequences deposited under accessions KB405099-KB441797; then, remaining unassigned BESs were aligned to sequences AOCW01000001-AOCW01191454, because these datasets do not completely overlap (KBs represent superscaffolds assembled from AOCWs; however, some AOCWs remained unassembled and do not exist in KB dataset). The BLAST algorithm was optimized for highly similar sequences (word size, 28; match/ mismatch scores, 1/-2; and gap costs, linear), and one match with the highest score was selected. BESproducing alignments of sequence identity value above $95 \%$ were checked for the possibility of base calling errors at mismatch sites, and in case of positive verification, appropriate scaffolds were considered as assigned.

Microsyntenic region analysis

In order to identify microsyntenic regions of narrowleafed lupin and nine Fabaceae species, L. angustifolius BAC and scaffold sequences with repetitive content were masked by RepeatMasker and Censor (Kohany et al. 2006) and subjected to comparative mapping. The following genome sequences were used: Arachis duranensis (Peanut Genome Project accession V14167, http://www.peanutbase.org), A. ipaensis (Peanut Genome Project accession K30076, http:/www. peanutbase.org), Cajanus cajan (Varshney et al. 2012) (project PRJNA72815, v1.0), Cicer arietinum (Varshney et al. 2013) (v1.0 unmasked, http:// comparative-legumes.org), G. $\max$ (Schmutz et al. 2010) (JGI v1.1 unmasked, http://www.phytozome. net), L. japonicus (Sato et al. 2008) (v2.5 unmasked, http://www.kazusa.or.jp), M. truncatula (Young et al. 2011) (strain A17, JCVI v4.0 unmasked, http://www. jcvi.org/medicago/), P. vulgaris (v0.9, DOE-JGI, and USDA-NIFA; http://www.phytozome.net), and Vigna radiata (Kang et al. 2014) (GenBank/EMBL/DDBJ accession JJMO00000000). The CoGe BLAST algorithm (Lyons et al. 2008) was used to perform sequence similarity analyses with the following parameters: e-value cutoff, 1e-20; word size, 8; gap existence cost, 5; gap elongation cost, 2; and nucleotide match/mismatch scores, $1 /-2$. Microsyntenic blocks were visualized using the Web-based Genome Synteny Viewer (Revanna et al. 2011) and Circos (Krzywinski et al. 2009).

Molecular marker generation and genetic mapping

Primers for molecular markers amplification were designed based on BESs with the use of Primer3 Plus software (Untergasser et al. 2007). To identify polymorphic loci, PCR amplification was carried out with DNA isolated from parental lines of the L. angustifolius mapping population, 83A:476 ( $\mathrm{D}=$ domesticated $)$ and P27255 (W=wild). PCR products were visualized by $2 \%$ agarose gel electrophoresis, purified with QIAquick PCR Purification Kit (Qiagen, Hilden, Germany), and sequenced on the ABIPRISM 3130 XL Genetic Analyzer (Applied Biosystems, Foster City, USA). Singlenucleotide polymorphisms (SNPs) were detected by the Cleaved Amplified Polymorphic Sequence (CAPS) approach (Konieczny and Ausubel 1993). Sequence differences such as sequence length polymorphism were performed by allele-specific PCR (AS-PCR) with primers anchored in polymorphic sites. Derived Cleaved Amplified Polymorphic Sequence (dCAPS) method, based on the use of mismatch PCR primers to introduce a restriction site into the polymorphic locus, 
was also used (Neff et al. 1998). Marker segregation was tested and the calculation of the chi-squared $\left(\chi^{2}\right)$ for Mendelian segregation in $F_{8}$ recombinant inbreed lines was done using the following expected segregation ratios: 0.4961 (maternal), 0.4961 (paternal), and 0.0078 (heterozygote). Probability calculation was based on $\chi^{2}$ and $2 d f$. The Map Manager QTXb20 freeware was used to localize new markers on the L. angustifolius genetic map (Kroc et al. 2014; Kamphuis et al. 2015). Graphic illustration of linkage groups was performed using MapChart (Voorrips 2002) software.

Molecular probes for fluorescence in situ hybridization

$B A C$ probes BAC DNA was isolated using QIAprep Spin Miniprep Kit (Qiagen, Hilden, Germany) according to the protocol obtained by Farrar and Donnison (2007) and labeled with digoxigenin-11-dUTP and/or tetramethylrhodamine-5-dUTP (Roche Diagnostics, Basel, Switzerland) by nick translation, as described by Jenkins and Hasterok (2007).

rDNA probes The wheat (T. aestivum var. Chinese spring) clone pTa794 (Gerlach and Dyer 1980) and A. thaliana 2.3-kb ClaI subclone (Unfried and Gruendler 1990) were used as 5S rDNA and 25S subunit of 45S rDNA reference sequences, respectively. rDNA probes as well as narrow-leafed lupin BAC clone $072 \mathrm{O} 21$ carrying 45S rDNA sequence (Książkiewicz et al. 2013) were labeled with digoxigenin-11-dUTP and/or tetramethyl-rhodamine-5-dUTP by nick translation (Roche Diagnostics, Basel, Switzerland).

L. angustifolius sequence 120E23_5 (GF110967.1) annotated as 5S rDNA (Książkiewicz et al. 2013) was labeled with tetramethyl-rhodamine-5-dUTP (Roche Diagnostics, Basel, Switzerland) by PCR according to Hasterok et al. (2004).

Oligonucleotide probes To develop SSR-based probes, the particular motifs of sequences were synthesized and $5^{\prime}$ tailed, (ATCCTC $)_{3}$, $(\mathrm{GATAG})_{3}$, and $(\mathrm{AGG})_{5}$ with digoxigenin-11-dUTP and $(\mathrm{AG})_{8},(\mathrm{CTCC})_{4}$, and $(\mathrm{CC})_{8}$ with biotin (Sigma Aldrich, St. Louis, USA).

Chromosome preparation

Squash preparations of mitotic chromosomes of L. angustifolius, L. luteus, and L. albus as well as of
T. aestivum and N. tabacum were prepared from the root meristems according to the published protocols (Leśniewska et al. 2011; Kwiatek et al. 2013). Enzymatic maceration of fixed material was performed (40\% pectinase (Sigma Aldrich, St. Louis, USA), $3 \%$ cellulase (Sigma Aldrich, St. Louis, USA), and $1.5 \%$ "Onozuka" cellulase (Serva Electrophoresis, Heidelberg, Germany). Dissected meristematic tissues were squashed on alcohol-cleaned slides in $60 \%$ acetic acid. The quality of slides was checked under a phasecontrast microscope BX41 (Olympus, Tokyo, Japan). The slides were stored in $-20{ }^{\circ} \mathrm{C}$ or directly used for FISH.

\section{FISH procedure}

FISH procedure was carried out according to the protocol optimized for L. angustifolius (Leśniewska et al. 2011). Immunodetection of digoxigenin-labeled DNA probes was conducted with FITC-conjugated antidigoxigenin primary antibodies (Roche Diagnostics, Basel, Switzerland), whereas biotin was labeled with streptavidin-Cy3 (Sigma Aldrich, St. Louis, USA). Chromosomes were counterstained with $2 \mu \mathrm{g} / \mathrm{mL}$ DAPI (Sigma Aldrich, St. Louis, USA) in Vectashield antifade mounting medium (Vector Laboratories, Burlingame, USA). Slides were analyzed with an epifluorescence microscope BX60 (Olympus, Tokyo, Japan) using the Cell_F software. The images of FISH signals and stained chromosomes were captured using a CCD monochromatic camera and superimposed using Micrografx (Corel, Ottawa, Canada) Picture Publisher 8 software.

\section{Results}

\section{BAC clone characterization}

To increase the chance of selecting single-locus BACs, which are required for integration of $L$. angustifolius genetic and cytogenetic maps, the sequence-specific probes used for BAC library screening were anchored in the sequences of four genes involved in nitrogen fixation, a process that is specific to legume plants, ENOD40, NOD26, NOD45, and AAT-P2. Altogether, $42 \mathrm{BAC}$ clones yielded positive hybridization signals and were divided into independent libraries. The ENOD40 library contained $21 \mathrm{BACs}$, the NOD26 
library contained 5 BACs, the NOD45 library contained 9 BACs, and the AAT-P2 library contained 7 BACs. However, after Sanger sequencing with probe-specific primers, only $16 \mathrm{BACs}$ were confirmed to carry the ENOD40 sequence, and 5, 8, and 5 BACs were confirmed to carry the NOD26, NOD45, and AAT-P2 sequences, respectively.

The BAC clones were grouped within the four libraries based on their sequence polymorphism determined by sequencing with gene-specific primers. Fourteen of the BAC clones that carried the ENOD40 gene sequence shared $100 \%$ nucleotide identity in the amplified sequences and were annotated as carrying ENOD40variant 1 (Table 1). Two representative clones from this group were selected for in-depth studies, $008 \mathrm{O} 20$ and 131P18. The other two BAC clones that carried the ENOD40 gene sequence, 059F07 and 068H10, were annotated as carrying ENOD40-variant 2 and ENOD40-variant3, respectively (Table 1). Likewise, the NOD26 BAC clones were divided into the following three groups: clones $051 \mathrm{D} 03$ and $127 \mathrm{~N} 17$ carrying NOD26-variant1, clone 087F06 carrying NOD26-variant2, and clones $123 \mathrm{D} 01$ and 066106 carrying NOD26variant 3 (Table 1). The NOD45 BAC clones formed one homologous group carrying one gene variant. The $A A T$ $P 2$ BAC clones also formed one homologous group carrying one gene variant (Table 1).

To saturate the cytogenetic map of $L$. angustifolius, the set of 42 BAC clones was supplemented with 13 other BACs selected from the narrow-leafed lupin BAC library. These clones carry the sequences of genes that encode $A S, G S 1$, and $P E P C$. We also analyzed two BAC clones that revealed centromere-specific FISH signals (103O20 and 134A23) as well as two clones previously characterized as carrying rDNA sequences (072O21 and 120E23) (Książkiewicz et al. 2015). Altogether, 59 BAC clones were selected for further analysis using cytogenetic and molecular approaches (Table 1).

\section{BES analysis}

To obtain sequence anchors for molecular marker development and L. angustifolius genome sequence survey, a set of 57 BAC clones were BAC-end sequenced, yielding 104 BESs (GenBank accession numbers KU678228-KU678331) with an average length of 568 bp and GC content $34.3 \%$. The RepeatMasker annotation marked $3434 \mathrm{bp}$ out of a total BES length of $59,047 \mathrm{bp}(5.82 \%)$ as repetitive elements. These repeats included long interspersed nuclear elements (LINEs; $0.41 \%$ ), Ty1/Copia (2.53\%) and Gypsy/ DIRS1 $(0.65 \%)$ retrotransposons, and DNA transposons $(0.67 \%)$ as well as single and low complexity repeats (1.49 and $0.07 \%$, respectively). Predicted nonrepetitive gene-coding sequences were annotated in 28 of the $3^{\prime}$ BAC ends and in 20 of the $5^{\prime}$ ends (Online resource 2).

BAC clones as narrow-leafed lupin chromosome markers

FISH was performed using 59 BACs as the molecular probes. To identify cytogenetic chromosome markers, the BAC probes were subjected to numerous FISH reactions on metaphase mitotic chromosomes of L. angustifolius. Various combinations of BAC-FISH reactions were performed using two probes simultaneously. Forty BACs gave single-locus type signals and were considered as chromosome-specific markers.

The following BACs, which originated from different libraries, localized in the same chromosome regions, but the regions differed from one library to the other: ENOD40 (008O20, 018I03, 033G07, 131P18, and 132P08), NOD26 (051D03 and 127N17), NOD45 (004L17, 008A17, 038J06, 061F03, 067J14, 122B05, 138D07, and 138H12), and AAT-P2 (026B19, 040A13, 058G22, 114O14, and 137N08). However, clones carrying different sequence variants, such as $008 \mathrm{O} 20$, 131P18 (ENOD40-variant1), 059F07 (ENOD40-variant2), and $068 \mathrm{H} 10$ (ENOD40-variant3), as well as 051D03, 127N17 (NOD26-variant1), and 087F06 (NOD26-variant2), were localized to different narrowleafed lupin genome regions. The positions of BACs 123D01 and 066I06 (NOD26-variant3) in relation to the other two NOD26 variants could not be determined because of the repetitive character of these clones. The localization of all chromosome-specific markers (both newly developed and already existing) was confirmed, allowing us to comprehensively verify physical linkage by direct visualization of reciprocal clone positions in narrow-leafed lupin chromosomes (Fig. 1a-e and Online resource 3).

The L. angustifolius 5S (120E23_5) and 25S (072O21) rDNAs were analyzed with reference rDNA sequences that are commonly used in FISH reactions. The mutual FISH mapping of $25 \mathrm{~S}$ rDNA probe (A. thaliana 2.3-kb ClaI sub-clone) with BAC $072 \mathrm{O} 21$ carrying the fragment of $45 \mathrm{~S}$ rDNA sequence 


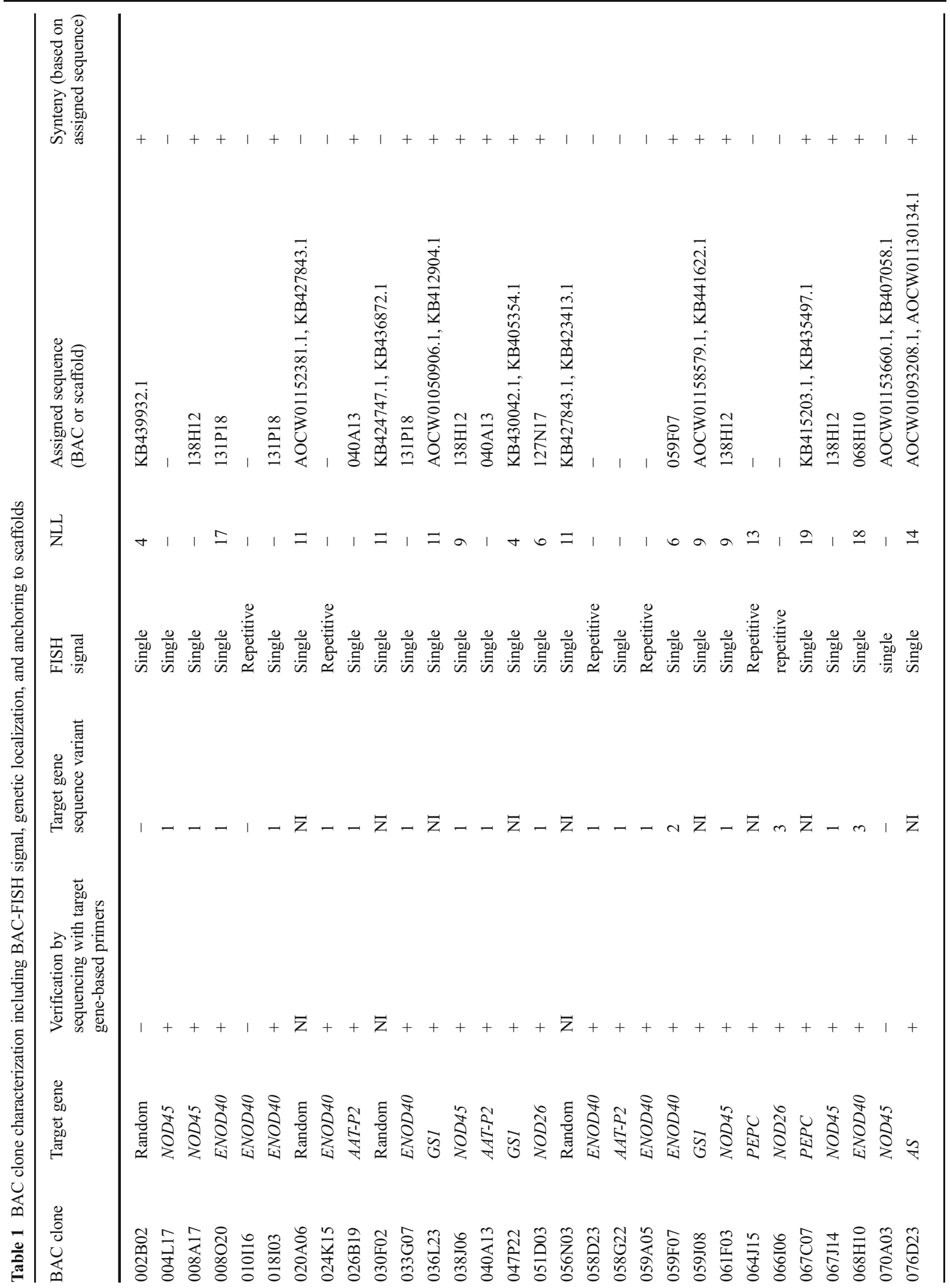




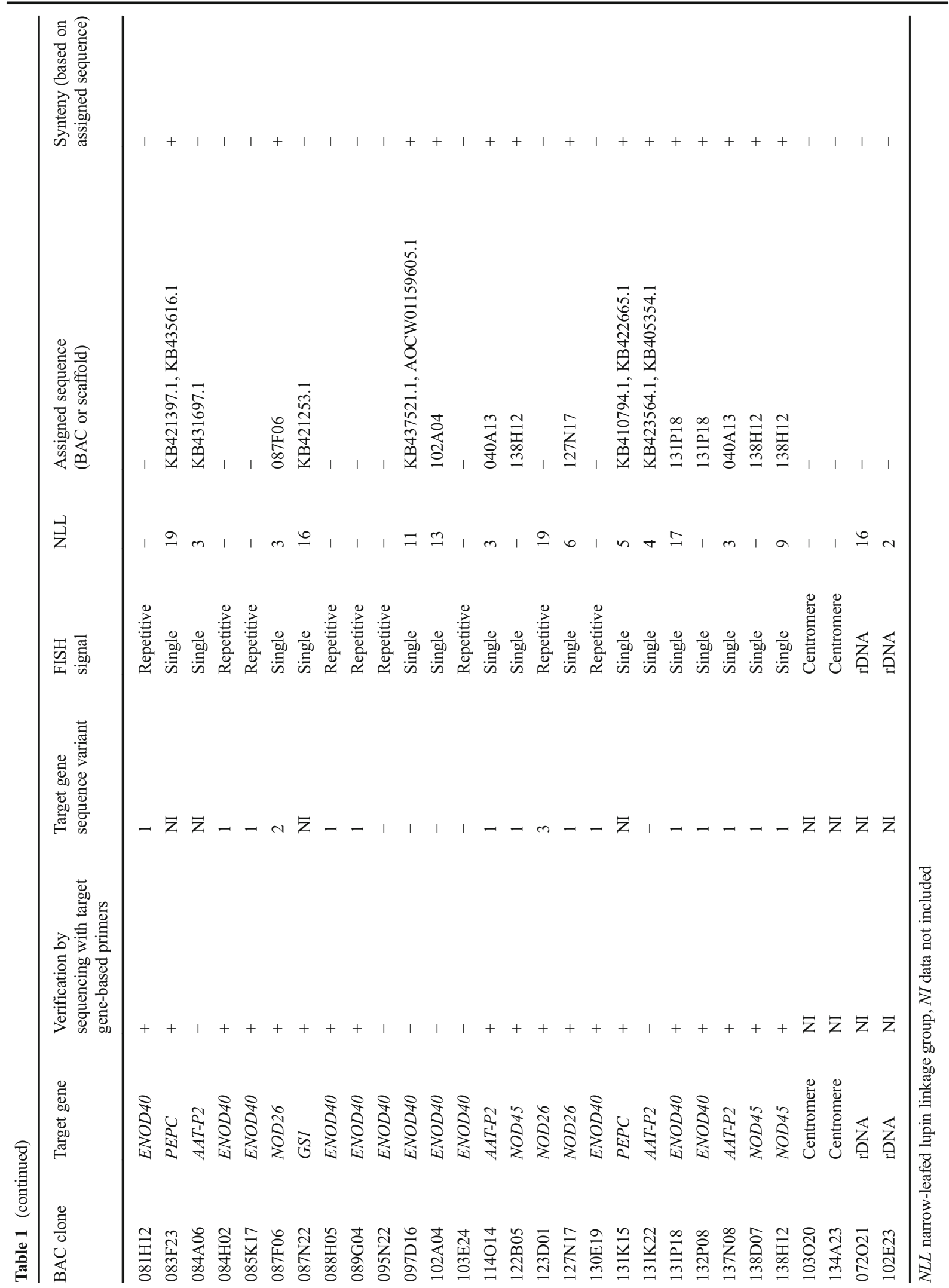




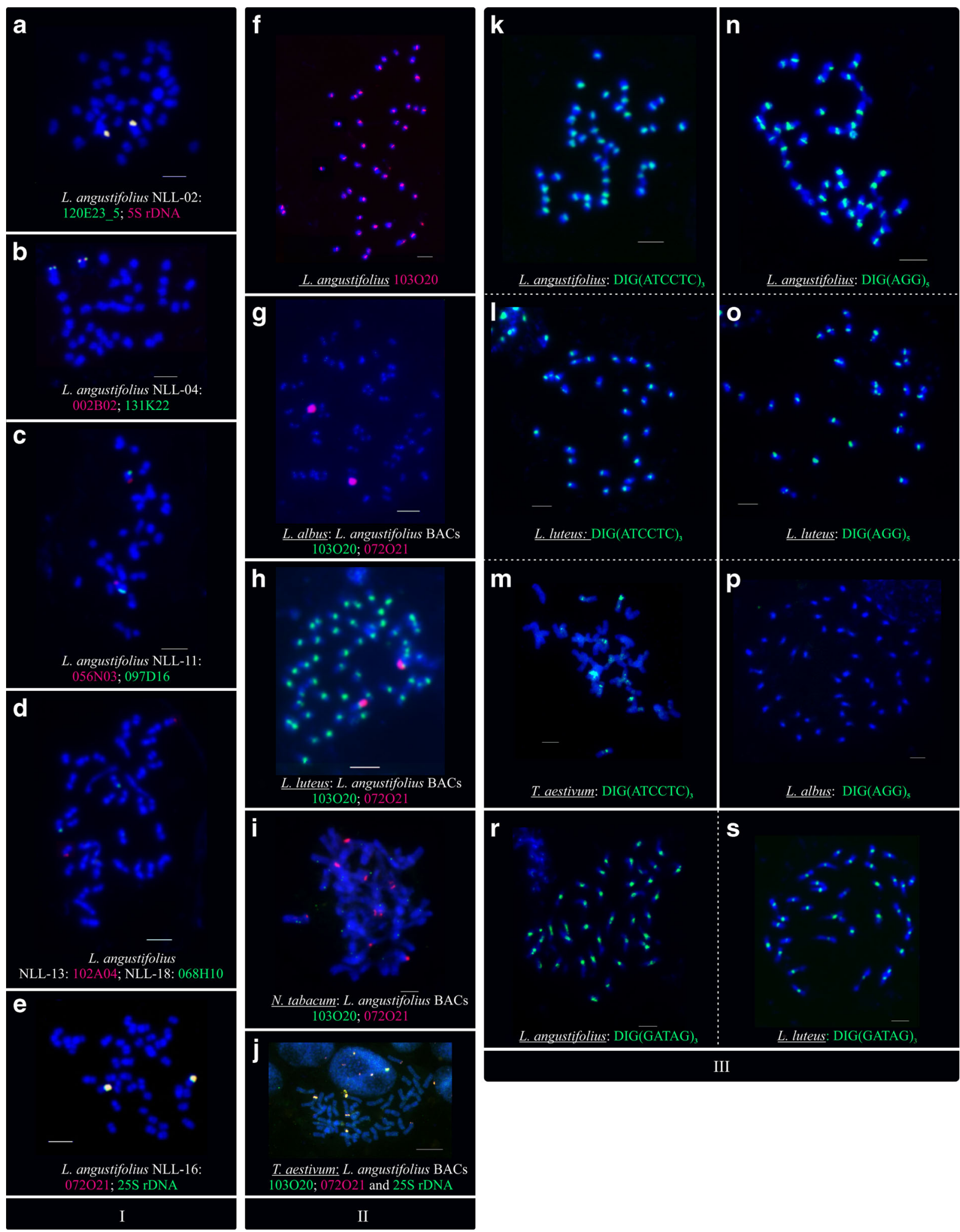


Fig. 1 Localization of BAC-based chromosome-specific markers obtained as a useful toolbox for comprehensive analysis of Lupinus angustifolius genome and intergeneric comparative studies. I. Assignment of linkage groups to their corresponding chromosomes with BAC clone and rDNA sequences as FISH probes, a NLL-02: 120E23_5 (D), 5S rDNA (R); b NLL-04: 002B02 (R), 131K22 (D); c NLL_11: 056N03 (R), $097 \mathrm{D} 16$ (D); d NLL-13: 102A04 (R), NLL-18: 068H10 (D); and e NLL-16: $072 \mathrm{O} 21$ (R), 25SrDNA (D). II. Centromere-specific BAC clone $103 \mathrm{O} 20$ (D) as a tool for comparative analysis of centromere sequence divergence in plant chromosomes, $\mathbf{f} L$. angustifolius, $\mathbf{g}$ L. albus, $\mathbf{h}$ L. luteus, $\mathbf{i} N$. tabacum, and $\mathbf{j} T$. aestivum. BAC clone $072 \mathrm{O} 21(\mathrm{R})$ carrying the $25 \mathrm{~S}$ rDNA subunit of $45 \mathrm{~S}$ rDNA was used as the BAC-FISH reaction control. III. Labeled SSRanchored oligonucleotides as a tool for distinguishing three lupin species and T. aestivum, identification of $\mathbf{k}-\mathbf{m}$ ATCCTC, $\mathbf{r}-\mathbf{s}$ GATAG, and $\mathbf{n}-\mathbf{p}$ AGG SSRs in chromosomes of $L$. angustifolius, L. luteus, T. aestivum, and L. albus. BAC clone DNA was labeled with tetramethylrhodamine-5-dUTP (R-red signal) or digoxigenin-11-dUPT (D-green signal). Overlapping clones produced yellow signals. Chromosomes were counterstained with DAPI. Scale bar $=5 \mu \mathrm{m}$ (L. angustifolius, L. albus, and L. luteus) and $10 \mu \mathrm{m}$ (T. aestivum and N. tabacum)

(HR864186.1) (Książkiewicz et al. 2015) confirmed their localization in the same locus (Fig. 1e). Furthermore, the FISH also confirmed that the genetic marker 120E23_5 carrying 5S rDNA sequence (Książkiewicz et al. 2015) corresponded to the 5S rDNA (T. aestivum clone pTa794) locus (Fig. 1a). These clones/sequences constitute genetic and cytogenetic markers for rRNA genes in the narrow-leafed lupin genome.

Two L. angustifolius clones, 103O20 and 134A23, generated strong centromere-specific signals in all 20 chromosomes of the narrow-leafed lupin. Whole-BAC clones were used as molecular probes to follow their homology in four species, two in the Lupinus genus (L. albus and L. luteus), and two unrelated species
(N. tabacum and T. aestivum). Centromere-specific BACs revealed strong hybridization signals in all centromeres in yellow lupin (L. luteus) chromosomes, whereas no specific signal was detected in white lupin (L. albus), tobacco, and wheat chromosomes (Fig. 1f-j).

Based on the results of the bioinformatic analysis of centromere-specific clone sequences (see "BAC clone sequencing and annotation" section), six SSR-specific FISH probes were designed and cytogenetically mapped. The SSR-FISH assay revealed clear centromere signals on L. angustifolius (Fig. 1k, n, r) and L. luteus (Fig. 11, o, s) chromosomes for SSR probes (AGG) $)_{5}$ (Fig. 1n-p), $(\text { GATAG })_{3}$ (Fig. 1r, s), and (ATCCTC $)_{3}$ (Fig. 1k-m) and very weak or no signal with probes $(\mathrm{AG})_{8},(\mathrm{CTCC})_{4}$, and (CC) ${ }_{8}$. All SSR probes gave specific, but not centromerespecific, FISH hybridization patterns on T. aestivum chromosomes (Fig. 1m) and can serve as wheat chromosome markers (Table 2). No hybridization signal was detected for any of the SSR probes on L. albus (Fig. 1p) and N. tabacum chromosomes.

\section{BAC clone sequencing and annotation}

BAC clones for sequencing were selected based on the following two criteria: type of BAC-FISH signal (single-locus clones were preferred) and target gene sequences represented. In total, 11 BAC clones were subjected to whole-insert sequencing, 9 carrying analyzed genes and 2 that were physically located in centromere regions of $L$. angustifolius chromosomes. Genespecific BAC clones were selected from the following libraries: ENOD40 (059F07, 068H10, and 131P18 carrying different gene sequence variants and 102A04 with

Table 2 Characterization of FISH signals detected for SSR-specific probes

\begin{tabular}{|c|c|c|c|c|c|}
\hline SSR motif & $\begin{array}{l}\text { L. angustifolius } \\
(2 \mathrm{n}=40)\end{array}$ & $\begin{array}{l}\text { L. luteus } \\
(2 \mathrm{n}=52)\end{array}$ & $\begin{array}{l}\text { L. albus } \\
(2 \mathrm{n}=50)\end{array}$ & $\begin{array}{l}\text { T. aestivum } \\
(2 \mathrm{n}=42)\end{array}$ & $\begin{array}{l}\text { N. tabacum } \\
(2 \mathrm{n}=48)\end{array}$ \\
\hline DIG(ATCCTC $)_{3}$ & Centromere & Centromere & ND & Signals on several chromosomes & ND \\
\hline DIG(GATAG) $)_{3}$ & Centromere & Centromere & ND & $\begin{array}{l}\text { Signals on several chromosomes, two } \\
\text { dominant loci }\end{array}$ & ND \\
\hline $\mathrm{DIG}(\mathrm{AGG})_{5}$ & Centromere & Centromere & ND & Signals on several chromosomes & ND \\
\hline $\mathrm{Btn}(\mathrm{AG})_{8}$ & $\begin{array}{l}\text { Very weak signals dispersed on } \\
\text { all lupin chromosomes }\end{array}$ & ND & ND & Signals on two chromosome pairs & ND \\
\hline $\mathrm{Btn}(\mathrm{CTCC})_{4}$ & $\begin{array}{l}\text { Very weak signals dispersed on } \\
\text { all lupin chromosomes }\end{array}$ & ND & ND & Signals on three chromosomes & ND \\
\hline $\mathrm{Btn}(\mathrm{CC})_{8}$ & $\begin{array}{l}\text { Very weak signals dispersed on } \\
\text { all lupin chromosomes }\end{array}$ & ND & ND & $\begin{array}{l}\text { Dominant signals on one chromosome pair, } \\
\text { weak signals in two chromosome pairs }\end{array}$ & ND \\
\hline
\end{tabular}

$D I G$ digoxigenin-labeled, Btn biotin-labeled, $N D$ none detected 
no ENOD40 sequence), NOD26 (087F06, 123D01, and $127 \mathrm{~N} 17$ carrying various gene copies), NOD45 (138H12), and AAT-P2 (040A13). The BAC clone lengths ranged from 14,351 to $108,291 \mathrm{bp}$ that is consistent with Kasprzak et al. (2006), where the average insert size in the library was estimated to be $\sim 100,000$ bp. GC content varied from 30.5 to $33.8 \%$ (32.6\% on average). Repetitive content in BACs varied from 0.96 to $16.73 \%$. The most abundant were long terminal repeat (LTR) retrotransposons (Ty1/Copia and Gypsy/DIRS1) followed by DNA transposons. The average number of coding sequences within the BAC clones was established as 16 genes/100 kbp (Table 3 and Online resource 4).

The assembly procedure of BAC clones that had generated BAC-FISH signals in centromere regions of L. angustifolius chromosomes resulted in generation of numerous small contigs for the clone 134A23 (954 sequences with minimum, mean, and maximum lengths of 183,436 , and $1159 \mathrm{nt}$, respectively) and one larger contig for $103 \mathrm{O} 20$ (3458 nt). These sequences displayed high GC (54.3\%) and SSR contents $(92.5 \%)$ and contained almost no gene-coding sequences (Table 3). The only annotated gene was "spindle pole body protein" ( $p c p 1)$, which was shown to be involved in mitotic sister chromatid segregation (Flory et al. 2002).

SSR Finder was used to characterize more precisely the SSR motifs within centromere-BAC inserts. Clustering of repeats differing by reading frames or reversecomplement reading revealed two types of SSRs that were the most frequent, trinucleotides grouped as "GGA/AGG/ GAG/CCT/CTC/TCC" and hexanucleotides grouped as
“ATCCTC/TCCTCA/CCTCAT/CTCATC/TCATCC/ CATCCT/AGGATG/GGATGA/GATGAG/ATGAGG/ TGAGGA/GAGGAT." The trinucleotide group constituted $23.0 \%$ of the whole sequence, while the hexanucleotide group constituted $21.9 \%$. The other SRR motifs were grouped as follows: pentanucleotides "AGGAT/GGATA/GATAG/ATAGG/TAGGA/ATCCT/ TCCTA/CCTAT/CTATC/TATCC" (9.2\%), dinucleotides "AG/GA/TC/CT" (8.6\%) and "CC/GG" (8.1\%), and tetranucleotides "CCCT/CCTC/CTCC/TCCC/AGGG/ GAGG/GGAG/GGGA" (1.3\%). More complex internal sequence alignments showed that the vast majority of identified SSR motifs were ordered in longer structures that consisted of tandemly repeated units. Considering the average length of MiSeq v2 reads and the limitations of sequence assembly algorithms, we estimated that these structures were at least $200 \mathrm{bp}$ in length. Annotation of the two longest reconstructed structures of 229 and $369 \mathrm{bp}$ revealed that they were composed of two types of SSRs, the GGA and ATCCTC groups. In these two structures, the first SRR type was repeated 47 or 60 times and the second SRR type was repeated 17 or 27 times, respectively. However, considering the high probability of false positive overlapping of repeat-rich reads during sequence assembly, these numbers are only low-fidelity estimations. The raw BAC sequencing data has been deposited in GenBank (040A13: KU678217, 059F07: KU678219, 068H10: KU678221, 087F06: KU678218, 102A04: KU678222, 123D01: KU678220, 127N17: KU678223, 103O20: KU724479, 134A23: KU724480-KU725433, 131P18: KU678224, and 138H12: KU678225KU678227).

Table 3 Characterization of the composition of BAC clone sequenced

\begin{tabular}{llllll}
\hline BAC clone & Length (bp) & \%GC & Percent of RE & RE type & No. of CDS \\
\hline 040A13 & 78,339 & 31.5 & 2.7 & Ty1/Copia, simple repeats & 11 \\
059F07 & 96,808 & 32.8 & 4.28 & Ty1/Copia, Gypsy/DIRS1, simple repeats & 16 \\
068H10 & 95,152 & 30.5 & 6.65 & Ty1/Copia, simple repeats & 10 \\
087F06 & 92,290 & 32.6 & 1.51 & DNA transposons, simple repeats & 19 \\
102A04 & 95,483 & 33.1 & 2.71 & Simple repeats & 19 \\
123D01 & 94,935 & 33.4 & 16.73 & Ty1/Copia, Gypsy/DIRS1, DNA transposons, simple repeats & 19 \\
127N17 & 14,351 & 33.8 & 0.96 & Simple repeats & 16 \\
131P18 & 108,291 & 33.5 & 8.19 & Ty1/Copia, Gypsy/DIRS1, simple repeats & 14 \\
138H12 & 93,952 & 33.0 & 2.31 & L1/CIN4, simple repeats & 1 \\
103O20, 134A23 & $419,430^{\mathrm{a}}$ & 54.3 & 92.5 & Simple repeats & \\
\hline
\end{tabular}

REs repeat elements, $C D S$ coding sequence

${ }^{\text {a }}$ Total length of obtained multiple scaffolds 
Anchoring BAC clones to the draft genome sequence

To reconstruct longer regions of the genome, the sequences of BAC clones 123D01, 138H12, and 131P18 as well as $28 \mathrm{BESs}$ of the 14 clones carrying ENOD40-variant1 were aligned to the scaffolds of the narrow-leafed lupin draft genome sequence (Yang et al. 2013). Overlapping scaffolds were identified for both ends of the studied clones. Based on these alignments, supercontigs carrying merged BAC and scaffold sequences were assembled. The BACbased supercontigs consisted of 118,121 bp for 123D01, $171,311 \mathrm{bp}$ for $138 \mathrm{H} 12$, and $295,679 \mathrm{bp}$ for the set of 14 BACs and 10 scaffolds, including the 131P18 sequence. Then, to identify anchors of physical linkage and to group the remaining clones into contigs, all the BESs were aligned to sequenced BAC clones and to the new BACbased supercontigs. Of the 104 BESs analyzed, 62 shared high-sequence identity (at least $97 \%$ but mostly 99-100 \%) with BAC clone and BAC-based supercontig sequences. Based on the BES mapping, the 131P18, 138H12, 040A13, 123D01, and 127N17 sequences were shown to represent contigs composed of $14,7,4,2$, and 2 clones, respectively. These results are concordant with BAC clone clustering based on sequencing from genespecific primers. The alignment data are presented in Online resource 5.

To discover more nucleotide data related to analyzed cytogenetic landmarks, 33 BESs that did not match any of the BAC sequences but were from clones that yielded single-locus BAC-FISH signals were aligned to the scaffolds of the narrow-leafed lupin draft genome assembly (Yang et al. 2013). Lupin genome scaffolds were identified for all clones except 004L17 and 30 BESs from 16 clones aligned specifically to 27 scaffold sequences. The total length of the selected scaffolds was $462,589 \mathrm{bp}$, and the orientation of 26 of the scaffolds was determined by the location of two or more paired BESs.

Based on BES localization in the scaffolds, several other sets of physically overlapping clones were identified, one group of three clones (five scaffolds) and three groups of two clones (three to four scaffolds). Taking all the sequence data together, sequence representatives (whole inserts or genome scaffolds) were obtained for 37 of the 39 single-locus clones (Table 1). The list of BESs used for genome sequence screening is given in Online resource 6. Data on the assigned scaffolds including accession numbers, names, and lengths as well as basic statistics and coordinates of constructed alignments are presented in Online resource 7.
To supplement the information derived from wholeinsert sequence analysis of chromosome-specific cytogenetic markers, the sequences of 32 scaffolds that were assigned to single-locus BAC clones (564,809 bp) were subjected to comprehensive in silico repeat content analysis. RepeatMasker and Censor screening revealed that the frequencies of interspersed repeats in these scaffolds varied from 0 to $61.75 \%$. A high prevalence of retrotransposons, particularly the Ty1/Copia and Gypsy/DIRS1 types, was observed. Transposon occupancy was negligible and the identified sequences originated from just four main families, Helitron, hAT, MuLE-MuDR, and CMC/EnSpm (Table 4). Repetitive elements constituted about $16 \%$ of the scaffold sequences, but some single-locus clones revealed relatively high amounts of repetitive content, approximately $32 \%$ for a contig of three BACs (020A06, $030 \mathrm{~F} 02$, and $056 \mathrm{~N} 03$ ) and approximately $33 \%$ for clone 070A03. It should be noted that BAC clone sequences were not recovered in their entirety, because the lupin genome scaffolds were anchored to BAC ends and large gaps between them were to be expected. Consequently, the percentage values presented here should be considered as tentative estimates. Annotation data for the repeats, including sequence coordinates, $p$ values, and repeat family/type assignment, are given in Online resource 8.

Table 4 Percentage of repetitive sequences identified in scaffolds that represent single-locus BAC clones

\begin{tabular}{lc}
\hline Type $^{\text {a }}$ & Content (\%) \\
\hline DNA/RC/Helitron & 0.49 \\
DNA/hAT & 0.37 \\
DNA/MuLE-MuDR & 0.28 \\
DNA/EnSpm/CACTA & 0.16 \\
DNA/other & 0.18 \\
Total transposons & 1.48 \\
R/LTR/Copia & 6.71 \\
R/LTR/Gypsy & 4.48 \\
R/LINE/L1 & 1.84 \\
R/LINE/RTE & 0.10 \\
R/SINE/SINE2 & 0.08 \\
R/LTR/ERV1 & 0.05 \\
R/LTR/Pao & 0.03 \\
R/LINE/LOA & 0.00 \\
Total retrotransposons & 13.29 \\
Simple repeat & 1.02 \\
Total repeats & 15.78 \\
\hline
\end{tabular}

${ }^{\text {a }}$ Type, repetitive sequence type 
The 131P18 supercontig, which carries ENOD40variant1 and consists of 10 scaffolds (14 clones), was aligned to the NCBI Refseq and transcriptome sequences of three lupin species using BLAST. The supercontig sequence aligned to numerous annotated L. albus, L. luteus, and L. angustifolius gene sequences as well as to cDNA contigs, as shown in Fig. 2 and Online resource 9. The alignments indicate that this supercontig contains a gene-rich region. However, the majority of BACs that formed this contig produced repetitive BAC-FISH signals that were dispersed over numerous chromosomes, and only four of them turned out to be single-locus probes. Because all the BES coordinates and clone orientations on the draft genome assembly were deciphered, we were able to analyze the type of BAC-FISH signals in relation to the sequence composition. Briefly, the presence of two large Copia segments or one Copia and one Gypsy segment in some of the BAC clones was enough to produce repetitive signals in BAC-FISH. Similarly, the presence of Helitron together with one large Copia element produced repetitive BAC-FISH signals. On the contrary, the presence of LINE/L1 or hAT repeats was not related to the type of BAC-FISH signal produced (Online resource 10).
Genetic mapping

To assign selected BAC clones to linkage groups of the narrow-leafed lupin genetic map, we developed molecular markers to integrate the chromosomal and genetic maps. For primer design, we used 81 sequences derived from 39 single-locus BACs and 3 from repetitive sequences carrying target gene sequences.

Specific PCR products, amplified on a template ofDNA isolated from parental lines of the mapping population (83A476 and P27255), were obtained for all the BESderived and gene-specific primer pairs. Sequence polymorphism between parental lines was identified for 32 primer pairs, and molecular markers were designed as follows: 22 by CAPS, 6 by AS-PCR, and 2 by dCAPS (Online resource 11). The analyzed sequences often exhibited more than one difference in their nucleotide composition. Some SNPderived markers had additional length polymorphisms in the PCR products $\left(008 \mathrm{O} 20 \_5 \_3,030 \mathrm{~F} 02 \_3,059 \mathrm{~J} 08 \_3\right.$, 067C07_2, and 114O14_3). The obtained logarithm of the odds (LOD) scores of mapped markers varied from 4.6 to 20.6. Statistically significant deviation from the Mendelian segregation ratio ( $p$ value $<0.05$ ) was observed for five markers, namely 008020_5_3, 020A06_3, 051D03_5,097D16_3, and 131P18_3.

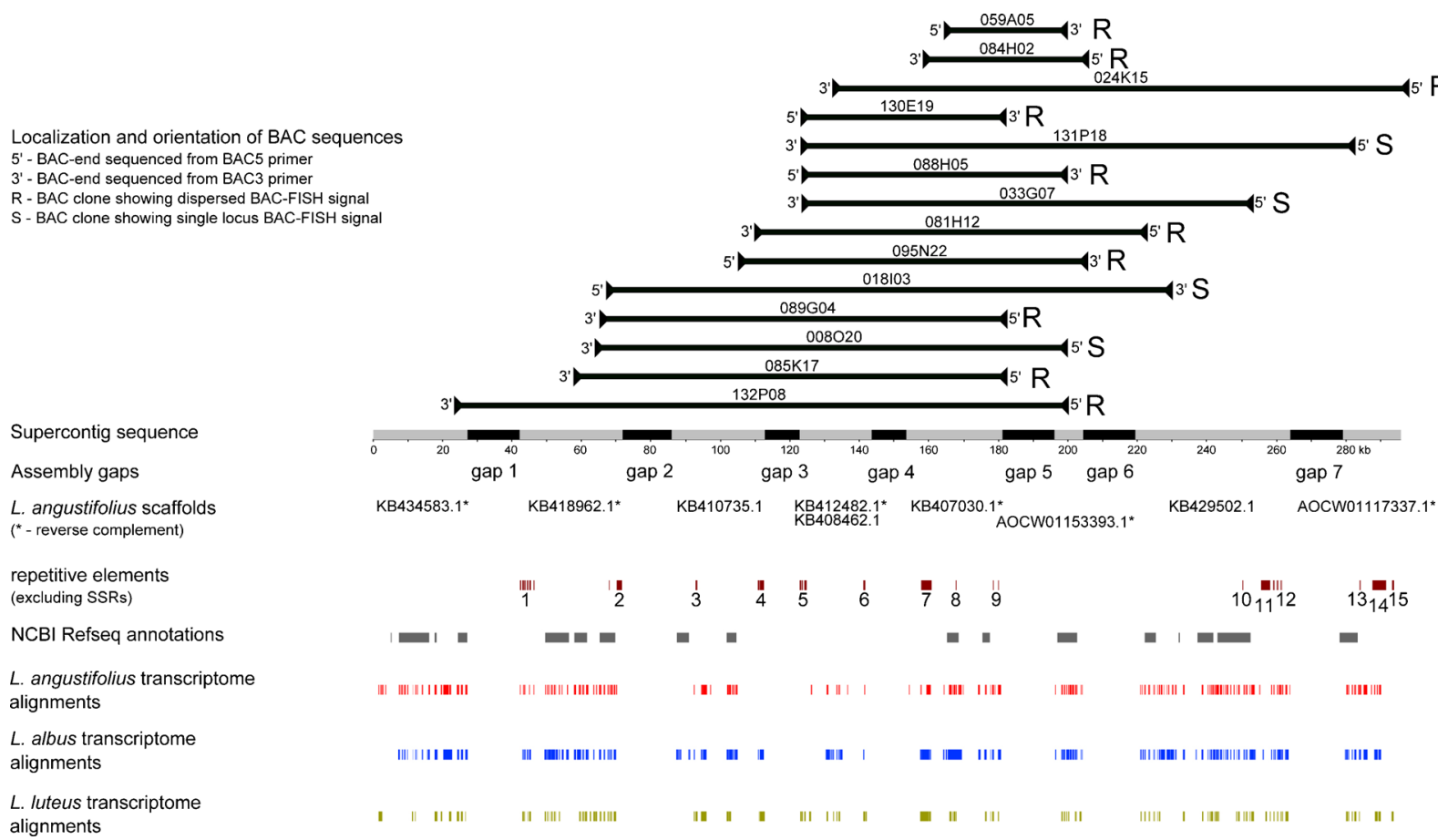

Fig. 2 Graphical representation of the alignment of the supercontig encompassing 14 BAC clones carrying ENOD40-variant1 with NCBI RefSeq and L. angustifolius, L. albus, and L. luteus transcriptome sequences 
The studied ENOD40-variant1 sequence was assigned to narrow-leafed lupin linkage group 17 (NLL-17) based on BES markers 008O20_5 and 131P18_3. Molecular markers 059F07_3 and 068H10_5 localized ENOD40variant 2 and ENOD40-variant3 in NLL-06 and NLL-18, respectively. Similarly, the NOD26 sequence variants were genetically mapped and assigned to three linkage groups (051D03 and 127N17 to NLL-06, 087F06 to NLL-03, and 123D01 to NLL-19). AAT-P2 molecular markers were anchored within BAC clones $114 \mathrm{O} 14$ and 137N08, which localized these sequences in L. angustifolius chromosome 3 (Lang 03). The supplementary, randomly selected BAC clones were genetically mapped and complemented the set of chromosome-specific markers. The $A S$ gene was mapped to NLL-14 based on the clone 076D23 sequence. BAC $131 \mathrm{~K} 15$, which contains the sequence of the PEPCvariant, was assigned to NLL-05, whereas clones $067 \mathrm{C} 07$ and 083F23 were assigned to NLL-19. The GS1 genes represented by clones 036L23, 047P22, 059J08, and 087N22 were assigned to NLL-04, NLL-09, NLL-11, and NLL-16, respectively. Moreover, the physical linkage of clones in five contigs was confirmed by genetic mapping of BES-derived markers, two in NLL-03 (114O14_3 and 137N08 5), three in NLL-09 (038J06 3, 061F03 5, and 138H12_5), three in NLL-11 (020A06_3, 056N03_3, and 030F02_3), two in NLL-17 (008020_5 and 131P18_5), and two in NLL-19 (067C07_3 and 083F23_3). Molecular marker sequences have been deposited in GenBank under accession numbers KU662037-KU662091.

All 32 new markers, including 5S rDNA and 45S rDNA, were distributed into 13 linkage groups of L. angustifolius (Online resource 12). Eleven markers derived from singlelocus BAC clones allowed us to assign all remaining unassigned linkage groups to chromosomes, thereby completing map integration for L. angustifolius (Fig. 3).

Cross-genus microsynteny of single-locus BAC clones

BAC clone sequences that yielded single-locus FISH signals on L. angustifolius metaphase chromosomes and
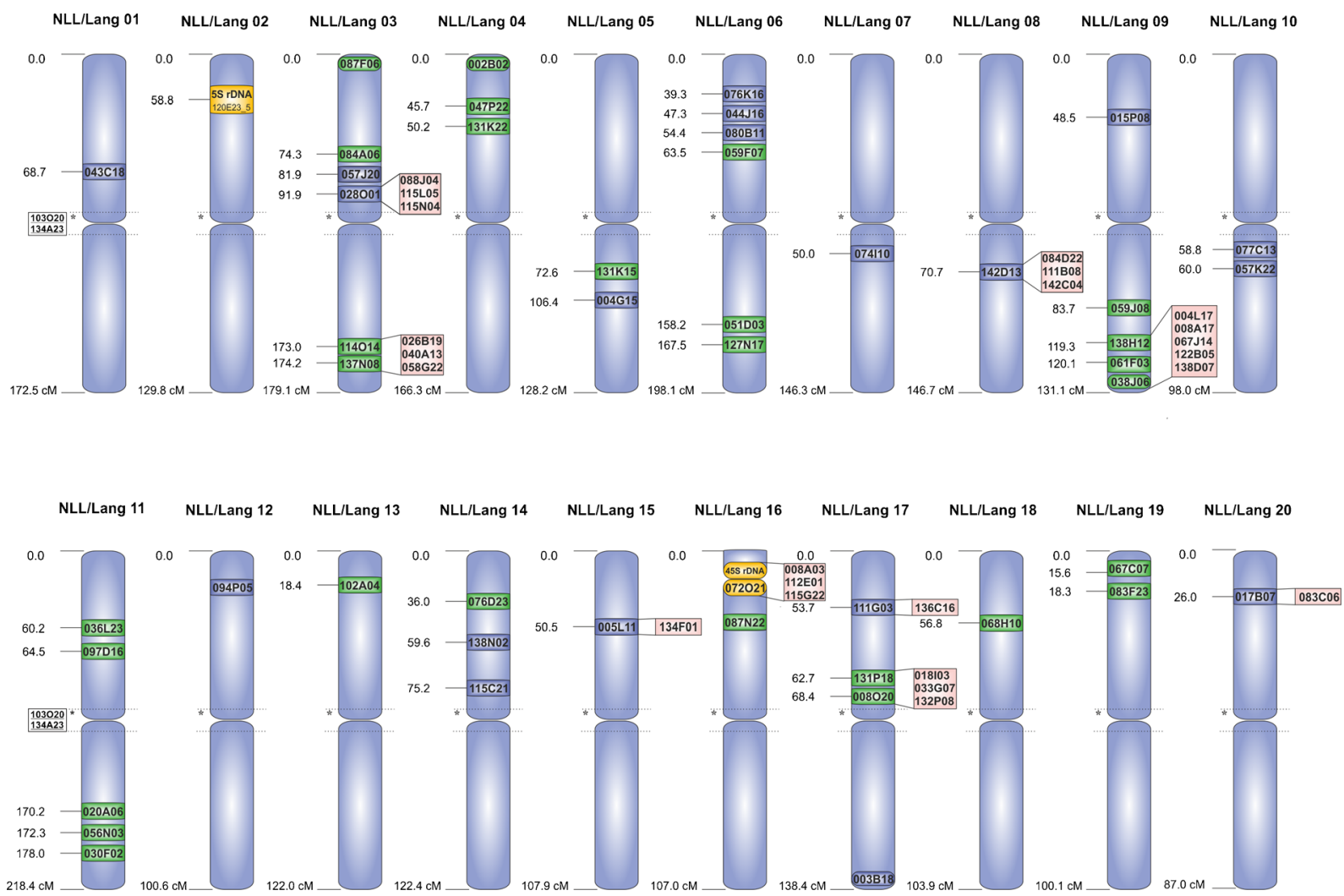

Fig. 3 Schematic representation of integrated linkage groups and chromosomes of Lupinus angustifolius. BAC clones used as parallel genetic and cytogenetic markers are shown as green (newly developed markers), blue (previously described markers), or

yellow (rDNA) and positioned according to the genetic distance (in $\mathrm{cM}$ ). The BAC clones established only as chromosomespecific markers are displayed in red and marked outside the chromosomes (lines correspond to defined chromosome loci) 
scaffolds anchored to these clones were subjected to comparative analysis, to determine if these BACs constitute cytogenetic landmarks of regions with conserved structure and shared synteny among several legume species. Syntenic patterns were observed for 23 sequences, representing (by physical linkage) 31 single-locus BAC clones. Data on all identified links of collinearity are provided in Online resource 13, and visualization of the most conserved syntenic blocks is presented in Fig. 4 and Online resource $14 \mathrm{a}-\mathrm{g}$.

Scaffolds anchored to $A S$ clone 076D23 revealed syntenic links to regions carrying the $A S$ gene on A. duranensis chromosome 10 (Ad10), A. ipaensis chromosome 10 (Ai10), C. arietinum chromosome 5 (Ca5), C. cajan chromosome 1 (Cc1), G. max chromosome 18 (Gm18), M. truncatula chromosome 3 (Mt3),
P. vulgaris chromosome 1 (Pv1), and $V$. radiata chromosome $2(\mathrm{Vr} 2)$ as well as to regions lacking the $A S$ gene on Ad3, Ai3, Ca6, Gm11, Gm5, Gm8, Mt8, Pv2, and Vr7 chromosomes and two Cc scaffolds. Such a pattern suggests ancient duplication in these species, followed by loss of excessive gene copies.

Scaffolds mapped to BAC clones 036L23, 047P22, 059J08, and 131K22 carrying the $G S$ gene shared synteny with loci in the genomes of other legume plants, all of which carried at least one homologous copy of the $G S$ gene. These observations provide clear evidence of ancient duplications that did not result in further elimination of additional gene copies. However, the overall pattern is more complex, because scaffolds anchored to 036L23 shared very well preserved synteny with regions lacking an annotated $G S$ gene copy.

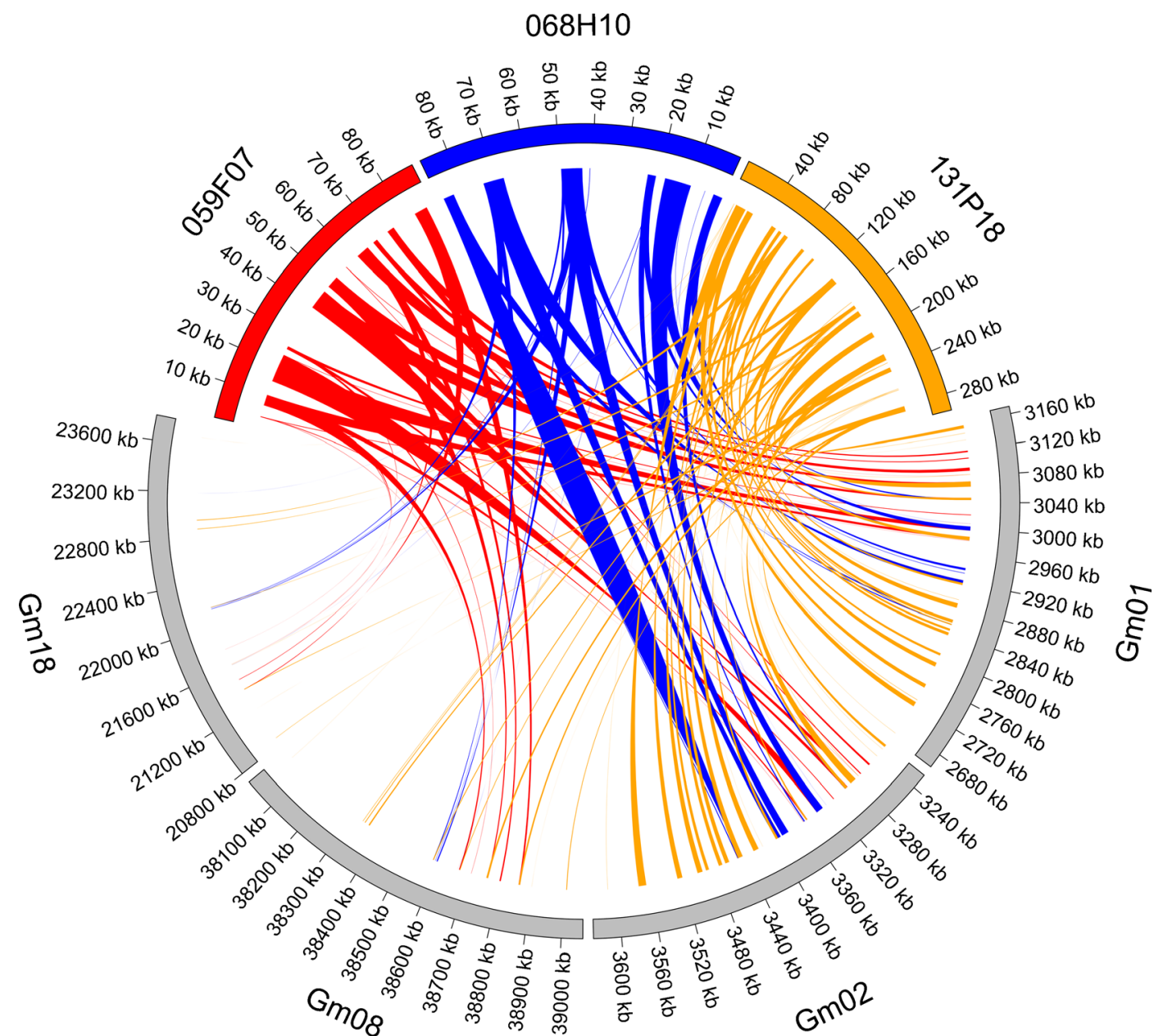

Fig. 4 Legume cross-genus microsyntenic patterns revealed for narrow-leafed lupin ENOD 40 clones (059F07, 068H10, 131P18) and Glycine max chromosomes (Gm01, Gm02, Gm08, Gm18).
Ribbons visualize homologous links identified by DNA sequence similarity. The chromosomes and $\mathrm{BAC}$ clones are not drawn to scale 
The set of scaffolds matching clones carrying PEPC had the most complex pattern of collinearity links, reflecting the numerous local duplications in the analyzed legume species. Two types of syntenic relationships were observed, to regions carrying a $P E P C$ gene (scaffolds mapped to clones $083 \mathrm{~F} 23$ and $131 \mathrm{~K} 15$ or $083 \mathrm{~F} 23$ itself) and to regions lacking a PEPC gene (scaffolds mapped to 067C07).

Three clones carrying an ENOD40 sequence showed links of conserved collinearity to the same regions on Ad3, Ad5, Ai3, Ai5, Ca2, Cc6, Gm1, Gm2, Gm8, Lj2, Mt5, Pv2, and Vr11. Such a distribution of syntenic blocks evidenced well-conserved remnants of duplication in Arachis and Glycine genomes (Fig. 4). Moreover, additional loci were identified on $\mathrm{Ca} 7, \mathrm{Gm} 18$, and $\mathrm{Mt} 8$ for 131P18; on Vr_scaffold_206 for 059F07; and on Pv3 for 131P18 and 059F07. Because the ENOD40 protein has only 14 amino acids, of which only 5 are conserved, we failed to identify this protein in corresponding legume regions due to the high number of putative false positive alignments.

Two BAC clones possessing a NOD26 gene, $087 \mathrm{~F} 06$ and $127 \mathrm{~N} 17$, revealed syntenic links to loci on $\mathrm{Ad} 7$, Ai8, Ca1, Cc11, Gm13, Gm15, Lj3, Mt2, Pv5, and Vr5. All these loci were annotated as "water-selective transport intrinsic membrane protein" or "major intrinsic protein," believed to be synonymous to NOD26 gene. Moreover, BAC clone 087F06 revealed synteny to loci on Ad9 and Ai9 annotated as "intrinsic protein," as well as to loci on Gm7, Gm8, Pv10, and Vr9 that lacked an annotated NOD26/intrinsic protein homolog.

BAC clone $138 \mathrm{H} 12$ with a NOD45 sequence showed conserved synteny to regions on chromosomes Ad1, Ad7, Ai1, Ai7, Ca2, Cc2, Gm14, Gm18, Gm2, Gm8, Lj2, Mt3, Mt5, Pv6, Pv8, and Vr6. However, no statistically significant alignment to a NOD45 gene sequence was identified in those regions or in the whole-genome assemblies of all the analyzed legume species, indicating that NOD45 is putatively a lupin-specific gene.

BAC clone 040A13 carrying a $A A T$ gene showed well-preserved collinearity to regions annotated as AAT on Ad6, Ai6, Ca4, Cc_Scaffold137572, Gm14, Gm17, Lj5, Mt1, Pv1, and Vr6. It also had syntenic links to regions lacking an annotated $A A T$ on $\mathrm{Ca} 5$, Gm4, Gm6, Mt3, Pv9, and Vr6. Duplicated regions had many local rearrangements, mostly insertions/ deletions.

The set of clones showing single-locus signals on metaphase chromosomes also included BAC clones selected randomly from the library. Three of the "random" clones revealed distinct patterns of synteny, two indirectly by BES-anchored scaffolds 002B02 and 097D16 and one directly by whole-insert sequence 102A04. Such an observation connects with the results of the linkage and cytogenetic mapping because these random clones were mapped in different chromosomes and linkage groups of $L$. angustifolius.

\section{Discussion}

Integrated map of the L. angustifolius genome as a platform for genus-wide cytogenetic studies

Integrative genome mapping can generate essential information for the improvement of sequence assembly in whole-genome sequencing and can provide a foundation for comparative genomics and evolutionary studies (Ren et al. 2012). Such integrated maps should facilitate and accelerate the ongoing second stage of whole-genome assembly of the narrow-leafed lupin by resolving the order and physical positions of linked markers and evaluating the size of the remaining gaps. Moreover, an integrated genetic/physical map may help to greatly improve the ordering of the reference genome superscaffolds into chromosomal "pseudomolecules," as was shown previously for potato (Sharma et al. 2013). Here, we report a consensus genome map for narrow-leafed lupin, which was achieved by combining cytogenetic and genetic mapping. On the integrated map, 71 BAC clones, and 5S rDNA and 25S subunits of $45 \mathrm{~S}$ rDNA sequences as chromosome-specific cytogenetic markers, tagged all 20 linkage groups of L. angustifolius (Fig. 3). The observed distribution of molecular markers is disproportionate among all the lupin chromosomes; i.e., six anchoring points are available for narrow-leafed lupin linkage group 3 (NLL-03) and chromosome 3 , whereas only one is available for NLL/Lang 01. Similar marker density on an integrated map for P. vulgaris has been reported (Fonseca et al. 2010). Nevertheless, the set of chromosome-specific BAC markers, together with rDNA sequences, characterizes the L. angustifolius karyotype and constitutes a useful tool for evolutionary studies within the Lupinus genus. The established platform of cytogenetic landmarks is sufficient to distinguish various chromosome regions including the determination of particular chromosome arms. The integrated narrow-leafed lupin map 
can be used to track chromosome rearrangements and their influence on genome evolution. Because special attention was paid to ensure that molecular markers were developed directly from single-locus BACs, the individual BACs applied as FISH probes corresponded to the same loci as the genetically mapped sequences. Such an approach is particularly important for species with small uniform chromosomes, particularly those that carry well-evidenced remnants of ancient wholegenome duplication or triplication (Kroc et al. 2014).

Map integration is useful for identifying genes/ regions that confer important traits and for the development of sequence-defined markers for breeding programs, as was shown in watermelon (Ren et al. 2012) and in narrow-leafed lupin (Książkiewicz et al. 2015). We have previously assigned 13 linkage groups to chromosomes by 20 BAC clones (Książkiewicz et al. 2015; Przysiecka et al. 2015). Narrow-leafed lupin linkage group 12 (NLL-12) was assigned to the corresponding chromosome using BAC 094P05 as a molecular probe (Narożna 2014). In the present study, we have saturated the genetic map with 30 new molecular markers representing genomic regions located in the 13 L. angustifolius linkage groups and analyzed the data that were obtained about the localization of the ENOD40, NOD26, NOD45, AAT-P2, AS, GS1, and $P E P C$ genes in these linkage groups. Genetic mapping followed by cytogenetic localization of single-locus BAC clones allowed us to assign six remaining linkage groups to corresponding chromosomes, thus complementing their reciprocal assignment in L. angustifolius. A distinctive feature of all but one single-locus BACs mapped in this study was their localization to distal chromosomal regions; only BAC 070A03 was localized close to the pericentromeric region. This observation is consistent with previous findings that gene density was generally higher in distal regions rather than other regions of chromosomes (Erayman et al. 2004). The BAC clone 070A03 sequence had various features that prevented its precise genetic mapping; therefore, this clone was not assigned to the narrow-leafed lupin genetic map.

Two L. angustifolius BACs, which in their BESs were annotated as containing $25 \mathrm{~S}$ subunit of $45 \mathrm{~S}$ and $5 \mathrm{~S}$ rDNA sequences, were identified previously (Książkiewicz et al. 2015). The presence of rDNA sequences in these BACs was confirmed in the present study by cytogenetic co-localization of conserved reference sequences $5 \mathrm{~S}$ and $25 \mathrm{~S}$ with $\mathrm{PCR}$ products amplified using BAC DNA as a template and BAC, respectively. FISH analysis of these clones/rDNA markers revealed the cytogenetic localization of $5 \mathrm{~S}$ rDNA and 18S-5.8S-25S (45S rDNA) rDNA loci in two distinct chromosome pairs. Together with BESbased genetic markers, these clones allowed two linkage groups to be assigned to chromosomes. The clone with $5 \mathrm{~S}$ rDNA was mapped to one locus in NLL-02. The clone containing $25 \mathrm{~S}$ subunit of $45 \mathrm{~S}$ rDNA was mapped to NLL-16. This clone was reported previously as a marker for the secondary constriction of the chromosome and for the nucleolar organizer in L. angustifolius. The results of the present study corroborate previous data on rDNA in L. angustifolius cv. Sonet (Naganowska and Zielinska 2002; Kaczmarek et al. 2009). However, for L. angustifolius cv. Emir, Hajdera et al. (2003) found three additional minor 5S rDNA signals. It is worth noting that Old World lupins vary not only in chromosome number $(2 \mathrm{n}=32-52)$ and genome size $(0.97-2.68 \mathrm{pg} / 2 \mathrm{C})$ but also in number and distribution of rDNA loci (Naganowska et al. 2003; Naganowska and Zielinska 2004). Thus far, chromosomal localization of rDNA has been performed in numerous papilionoid species, C. cajan (Varshney et al. 2012), L. japonicus (Ohmido et al. 2010), P. vulgaris (Fonseca et al. 2010), G. max (Krishnan et al. 2001), A. ipaensis and A. duranensis (Seijo et al. 2004), M. truncatula (Abirached-Darmency et al. 2005), C. arietinum (Abbo et al. 1994), and V. radiata (Bortoleti et al. 2012), as well as L. angustifolius (Naganowska and Zielinska 2002; Hajdera et al. 2003; Kaczmarek et al. 2009). Nevertheless, to the best of our knowledge, the present study is the first to provide information on linkage mapping of rDNA loci in the genus Lupinus.

AGG and GATAC repeats as species-specific markers of $L$. angustifolius and L. luteus centromeric and pericentromeric regions

Centromeres are easily recognized regions in chromosome morphology. Although their functions are conserved among all eukaryotes, their DNA sequences are highly diverse, even among closely related species (Ma et al. 2007b). Such diversity makes genetic mapping of centromeres a very challenging task. However, FISH offers the possibility of mapping centromeres cytogenetically. Two of the BAC clones (103O20 and 134A23) that were subjected to BAC-FISH yielded clear reproducible signals over the centromeres of all the 
L. angustifolius chromosomes. Bioinformatic analysis of these BACs revealed that centromeric and pericentromeric regions of narrow-leafed lupin consisted of SSRs ordered into two types of sequence blocks. The centromere-specific tandem repeats contained the trinucleotide and pentanucleotide SSRs AGG and GATAC, structured into long arrays. The presence of two distinct sequences formed by the two types of SSR repeats is surprising because most diploid species studied so far possess only a single centromeric satellite (Jiang et al. 2003). However, G. $\max$ centromeres have been reported to be composed of two distinct satellite repeats (GmCent-1 and GmCent-4) and retrotransposon-related sequences (GmCR) (Tek et al. 2010). Detailed analyses of centromeric DNA have been limited mainly to species within the Gramineae and Brassicaceae families. The rapid evolution of centromeric satellites has been correlated with the appearance of diverged and/or novel centromeric sequences in O. sativa and A. thaliana (Melters et al. 2013). Although research into centromeres in legume chromosomes is still in its infancy, centromeric satellites have been identified in several species; for example, a satellite Ljcen1 localized in L. japonicus and MtR3 in M. truncatula have been reported (Kulikova et al. 2004). Moreover, SSRs have been identified as a major constituent of centromeric DNA in legume species (Iwata et al. 2013). Knowledge on centromere structure and the composition of SSRs is still rudimentary; therefore, the presence of long clusters of SSRs in lupins needs further investigation.

The comparative cytogenetic mapping of BACs $103 \mathrm{O} 20$ and $134 \mathrm{~A} 23$ by their cross hybridization to chromosomes of four other species revealed signals in centromeres of L. luteus. However, no centromerespecific pattern was detected in L. albus or the other two species, N. tabacum and T. aestivum; the only signals visible were over some chromosome arms. This result supports the supposition of a closer evolutionary relationship between L. angustifolius and L. luteus compared with L. albus (Ainouche and Bayer 1999). Moreover, the synthetic oligonucleotides used in the FISH experiments revealed the trinucleotide and pentanucleotide SSR sites in the centromeric regions of chromosomes and confirmed the BAC-based results for the relationships among the analyzed species. Additionally, differences in the intensity of SSR-FISH signals were observed for $L$. angustifolius and L. luteus. This result suggests that the centromeric sequences of narrow-leafed and yellow lupins may have the same qualitative SSR composition, but their amounts or distributions may differ. Thus, the present study provides an indication that centromere-specific satellites are very divergent in the Lupinus genus.

L. angustifolius landmarks of conserved genome regions and tools for tracking ancient duplications in lupins

BACs that show single-locus signals on chromosomes have low repetitive sequence content and high exon density (Belarmino et al. 2012; Książkiewicz et al. 2013). The annotation of nine single-locus BAC sequences in the present study is in agreement with these findings. The gene to distance ratios (16 genes/100 kbp on average) are similar to values previously found for other L. angustifolius gene-rich regions, 17.9 genes/ $100 \mathrm{~kb}$ in three BACs spanning $263 \mathrm{~kb}$ (Książkiewicz et al. 2013) and 19.3 genes/100 kb in 017B07 clone of $\sim 109 \mathrm{~kb}$ (Książkiewicz et al. 2015). Those values are higher than an average gene density of 9.7 genes/100 kb derived from the draft genome assembly (57 806 genes over $598 \mathrm{Mb}$ ) (Yang et al. 2013). Average GC content in sequenced BAC clones converges with the genome assembly statistics (32.6 vs 33.6 \%) (Yang et al. 2013). Moreover, this value is consistent with previously published data for sequenced L. angustifolius BAC clones from this library, $33.1 \%$ of GC content in five clones counting $\sim 453 \mathrm{~kb}$ in total (Książkiewicz et al. 2013) and $33.5 \%$ GC content in five clones spanning $\sim 452 \mathrm{~kb}$ (Książkiewicz et al. 2015). In our study, average GC content in BESs was higher than in sequenced BACs (34.3 vs $32.6 \%$ ). The survey of 13,985 BESs carrying $8.89 \mathrm{Mbp}$ of sequence data also revealed moderately high GC content value (39\%) (Gao et al. 2011). Such an observation might be explained by the fact that BESs represent specific restriction site-associated regions. Therefore, BES-derived sequence statistics cannot be extrapolated to the whole genome. Repeat content in sequenced gene-rich BACs (0.96-16.73) is within the range observed for other gene-rich regions of the species (Książkiewicz et al. 2013, 2015) and corresponds with the value of $11.81 \%$ calculated for large BES dataset (Gao et al. 2011). The observed value is significantly lower than the total repeat content based on the K-mer plot model, estimated as $50 \%$ (Yang et al. 2013), which is consistent with well-known feature of gene-rich regions, namely, low repetitive element coverage. 
The sequences of gene-rich regions obtained in the present study may serve as a useful tool for evolutionary studies. Bioinformatic analysis of single-locus clones complemented the BAC-FISH approach by comparative mapping between L. angustifolius and several representatives of the main papilionoid clades. Direct sequence analysis provides additional information on genome sequence rearrangements, while FISH allows them to be visualized in chromosomes (Sobreira et al. 2011). Here, comparative mapping showed that at least 31 of the 40 chromosome-specific BAC anchors developed in this study were landmarks of well-conserved regions with cross-genus microsynteny. Considering that the level of synteny (i.e., the number and length of syntenic regions) is correlated with the evolutionary distance (Kaufmann and Frishman 2014), this set of clones should facilitate heterologous cytogenetic mapping of Lupinus species that are known to vary considerably in genome size and chromosome numbers. Sequence similarity analysis and cytogenetic mapping revealed the presence of more than one copy of ENOD40, NOD26, GS1, and PEPC gene sequences in the $L$. angustifolius genome. Comprehensive analysis at the gene and chromosome levels successfully localized all the studied gene copies into lupin linkage groups and chromosomes. The genetic positions of ENOD40, NOD26, PEPC, and GS1 in the genome support the hypothesis of ancient duplications, which contributed to the evolution of distinct copies of these genes. Distinct gene copies were also identified in other legume genomes, in the regions syntenic to L. angustifolius carrying NOD26, PEPC, and GS1 sequences. This finding implies that some of these duplication events must have occurred very early in the divergence history of papilionoid lineages. Indeed, some of these copies could be considered as remnants of an ancient whole-genome duplication that occurred in the progenitor line of papilionoids, including the genistoids (e.g., L. angustifolius), dalbergioids (Arachis spp.), millettioids (P. vulgaris, G. max, C. cajan, V. radiata), galegoids (M. truncatula, L. japonicus, C. arietinum), and Xanthocercis and Cladrastis (Schlueter et al. 2004; Pfeil et al. 2005; Cannon et al. 2006, 2015; Bertioli et al. 2009). Lupin whole-genome duplication is believed to have occurred before the divergence of New World and Old World clades (Cannon et al. 2015; Przysiecka et al. 2015), whereas some legume whole-genome duplication events occurred in recent evolutionary times, such as 13 million years ago in G. max and several million years ago in Arachis (Schmutz et al. 2010; Cannon et al. 2015).

The availability of the L. angustifolius draft genome sequence (Yang et al. 2013) and reference sequences of nine other legume species, A. ipaensis, A. duranensis, C. cajan (Varshney et al. 2012), C. arietinum (Varshney et al. 2013), G. $\max$ (Schmutz et al. 2010), L. japonicus (Sato et al. 2008), M. truncatula (Young et al. 2011), P. vulgaris (Schmutz et al. 2014), and V. radiata (Kang et al. 2014), has contributed significantly to lupin molecular studies. Despite the L. angustifolius genome sequence still being fragmented into numerous short scaffolds, the assembly, together with gene-based linkage maps, has opened unprecedented possibilities for comparative mapping and exploitation of microsyntenybased strategies. In the narrow-leafed lupin, the synteny shared with other sequenced legume genomes was harnessed to select candidate gene families underlying the vernalization independence locus $K u$ that confers an early flowering phenotype (Nelson et al. 2006), as well as to track the evolutionary history of duplicated chalcone isomerase-like genes (Przysiecka et al. 2015). Progress on the integration of genetic and chromosomal maps of L. angustifolius, together with the analysis of cross-genus sequence collinearity, represents a state-ofthe-art method of identifying clones that represent the most conserved and stable regions of the lupin genome. Two large repeat-free gene-rich regions from singlelocus BAC clones 004G15 and 080B11 served as anchors for comparative DNA sequence analysis between the genomes of L. angustifolius and G. max, which revealed identical order and orientation of microsyntenic blocks in the corresponding regions (Książkiewicz et al. 2013). The comparative analysis of gene-rich regions represented by single-locus BAC clone 017B07 provided novel evidence for shared synteny and ancient duplications in five of the legume species studied (M. truncatula, G. max, L. japonicus, P. vulgaris, and C. cajan) (Książkiewicz et al. 2015). Moreover, it has been demonstrated that ancient duplication regions are conserved among the main clades of Papilionoideae, dalbergioids (Arachis), genistoids (Lupinus), millettioids (Cajanus, Glycine, Phaseolus), robinioids (Lotus), and the inverted repeat-lacking clade (Medicago) (Lin et al. 2010; McClean et al. 2010; Reinprecht et al. 2013; Książkiewicz et al. 2015). However, until now, a very limited number of L. angustifolius chromosome landmarks that expose shared synteny have been developed, five clones from 
NLL-03, two from NLL-15, and one from NLL-06 (Książkiewicz et al. 2013, 2015; Przysiecka et al. 2015). In the present study, a milestone improvement of this resource has been achieved and the obtained data may contribute greatly to future lupin evolution studies at the genome and chromosome levels.

Acknowledgments The authors would like to thank Dr. Hua'an Yang from the Department of Agriculture and Food (Western Australia), Dr. Tomasz Pniewski, and Dr. Michał Kwiatek (Institute of Plant Genetics of the Polish Academy of Sciences) for the seeds of the L. angustifolius mapping population, N. tabacum, and T. aestivum, respectively. We are also grateful to Dr. Matthew Nelson from the University of Western Australia (currently, Royal Botanic Gardens Kew, England) for providing the basic mapping data. This research was funded by grants from the National Science Centre (https:/www.ncn.gov.pl), N N301 391939, 2011/03/ B/NZ2/01420, and 2013/08/T/NZ2/00796. The funders had no role in study design, data collection and analysis, decision to publish, or preparation of the manuscript.

\section{Compliance with ethical standards}

Conflict of interest The authors (Katarzyna Wyrwa, Michał Książkiewicz, Anna Szczepaniak, Karolina Susek, Jan Podkowiński, and Barbara Naganowska) declare that they have no conflict of interest.

Human and animal rights and informed consent This article does not contain any studies with human or animal subjects performed by the any of the authors.

Open Access This article is distributed under the terms of the Creative Commons Attribution 4.0 International License (http:// creativecommons.org/licenses/by/4.0/), which permits unrestricted use, distribution, and reproduction in any medium, provided you give appropriate credit to the original author(s) and the source, provide a link to the Creative Commons license, and indicate if changes were made.

\section{References}

Abbo S, Miller TE, Reader SM, Dunford RP, King IP (1994) Detection of ribosomal DNA sites in lentil and chickpea by fluorescent in situ hybridization. Genome 37:713-716

Abirached-Darmency M, Prado-Vivant E, Chelysheva L, Pouthier $\mathrm{T}$ (2005) Variation in rDNA locus number and position among legume species and detection of 2 linked rDNA loci in the model Medicago truncatula by FISH. Genome 48: 556-561

Ainouche AK, Bayer RJ (1999) Phylogenetic relationships in Lupinus (Fabaceae: Papilionoideae) based on internal transcribed spacer sequences (ITS) of nuclear ribosomal DNA. Am J Bot 86:590-607
Belarmino LC, Oliveira AR da S, Brasileiro-Vidal AC et al (2012) Mining plant genome browsers as a means for efficient connection of physical, genetic and cytogenetic mapping: an example using soybean. Genet Mol Biol 35:335-347

Bertioli DJ, Moretzsohn MC, Madsen LH et al (2009) An analysis of synteny of Arachis with Lotus and Medicago sheds new light on the structure, stability and evolution of legume genomes. BMC Genomics 10:1-11

Boersma JG, Pallotta M, Li C, Buirchell BJ, Sivasithamparam K, Yang H (2005) Construction of a genetic linkage map using MFLP and identification of molecular markers linked to domestication genes in narrow-leafed lupin (Lupinus angustifolius L.). Cell Mol Biol Lett 10:331-344

Bonifacio EM, Fonseca A, Almeida C, Dos Santos KG, PedrosaHarand A (2012) Comparative cytogenetic mapping between the lima bean (Phaseolus lunatus L.) and the common bean (P. vulgaris L.). Theor Appl Genet 124:1513-1520

Bortoleti KC, Benko-Iseppon MA, de Melo NF, Brasileiro-Vidal AC (2012) Chromatin differentiation between Vigna radiata (L.) R. Wilczek and V. unguiculata (L.) Walp. (Fabaceae). Plant Syst Evol 298:689-693

Brechenmacher L, Kim MY, Benitez M et al (2008) Transcription profiling of soybean nodulation by Bradyrhizobium japonicum. Mol Plant Microbe Interact 21:631-645

Cannon SB, Sterck L, Rombauts S et al (2006) Legume genome evolution viewed through the Medicago truncatula and Lotus japonicus genomes. Proc Natl Acad Sci U S A 103:1495914964

Cannon SB, May GD, Jackson SA (2009) Three sequenced legume genomes and many crop species: rich opportunities for translational genomics. Plant Physiol 151:970-977

Cannon SB, McKain MR, Harkess A et al (2015) Multiple polyploidy events in the early radiation of nodulating and nonnodulating legumes. Mol Biol Evol 32:193-210

Compaan B, Yang WC, Bisseling T, Franssen H (2001) ENOD40 expression in the pericycle precedes cortical cell division in Rhizobium-legume interaction and the highly conserved internal region of the gene does not encode a peptide. Plant Soil 230:1-8

Datta DB, Cai X, Wong PP, Triplett EW (1991) Immunocytochemical localization of glutamine synthetase in organs of Phaseolus vulgaris L. Plant Physiol 96:507-512

Dolezel J, Vrana J, Capal P, Kubalakova M, Buresova V, Simkova $\mathrm{H}$ (2014) Advances in plant chromosome genomics. Biotechnol Adv 32:122-136

Ellis THN, Poyser SJ (2002) An integrated and comparative view of pea genetic and cytogenetic maps. New Phytol 153:17-25

Erayman M, Sandhu M, Sidhu D, Dilbirligi M, Baenziger PS, Gill KS (2004) Demarcating the gene-rich regions of the wheat genome. Nucleic Acids Res 32(12):3546-3565

Farrar K, Donnison IS (2007) Construction and screening of BAC libraries made from Brachypodium genomic DNA. Nat Protoc 2:1661-1674

Fedorova M, van de Mortel J, Matsumoto PA et al (2002) Genome-wide identification of nodule-specific transcripts in the model legume Medicago truncatula. Plant Physiol 130: 519-537

Feng J, Liu Z, Cai X, Jan CC (2013) Toward a molecular cytogenetic map for cultivated sunflower (Helianthus annuus L.) by landed BAC/BIBAC clones. G3 (Bethesda) 3:31-40 
Figueroa DM, Bass HW (2010) A historical and modern perspective on plant cytogenetics. Brief Funct Genomics 9:95-102

Findley SD, Cannon S, Varala K et al (2010) A fluorescence in situ hybridization system for karyotyping soybean. Genetics 185 : 727-744

Flory MR, Morphew M, Joseph JD, Means AR, Davis TN (2002) Pcplp, an Spc110p-related calmodulin target at the centrosome of the fission yeast Schizosaccharomyces pombe. Cell Growth Differ 13:47-58

Foley RC, Jimenez-Lopez JC, Kamphuis LG, Hane JK, Melser S, Singh KB (2015) Analysis of conglutin seed storage proteins across lupin species using transcriptomic, protein and comparative genomic approaches. BMC Plant Biol 15:106

Fonseca A, Ferreira J, dos Santos TR et al (2010) Cytogenetic map of common bean (Phaseolus vulgaris L.). Chromosome Res 18:487-502

Gao LL, Hane JK, Kamphuis LG, Foley R, Shi BJ, Atkins CA, Singh KB (2011) Development of genomic resources for the narrow-leafed lupin (Lupinus angustifolius): construction of a bacterial artificial chromosome (BAC) library and BACend sequencing. BMC Genomics 12:521

Gaufichon L, Reisdorf-Crena M, Rothstein SJ, Chardon F, Suzuki A (2010) Biological functions of asparagine synthetase in plants. Plant Sci 179:141-153

Gerlach WL, Dyer TA (1980) Sequence organization of the repeating units in the nucleus of wheat which contain 5S rRNA genes. Nucleic Acids Res 8:4851-4865

Graham PH, Vance CP (2003) Legumes: importance and constraints to greater use. Plant Physiol 131:872-877

Griffith SM, Vance CP (1989) Aspartate aminotransferase in alfalfa root nodules: I. Purification and partial characterization. Plant Physiol 90:1622-1629

Hajdera I, Siwinska D, Hasterok R, Maluszynska J (2003) Molecular cytogenetic analysis of genome structure in Lupinus angustifolius and Lupinus cosentinii. Theor Appl Genet 107:988-996

Hasterok R, Draper J, Jenkins G (2004) Laying the cytotaxonomic foundations of a new model grass, Brachypodium distachyon (L.) Beauv. Chromosome Res 12:397-403

Hasterok R, Marasek A, Donnison IS et al (2006) Alignment of the genomes of Brachypodium distachyon and temperate cereals and grasses using bacterial artificial chromosome landing with fluorescence in situ hybridization. Genetics 173:349362

He Q, Cai Z, Hu T et al (2015) Repetitive sequence analysis and karyotyping reveals centromere-associated DNA sequences in radish (Raphanus sativus L.). BMC Plant Biol 15:105

Heslop-Harrison JS, Schwarzacher T (2011) Organisation of the plant genome in chromosomes. Plant J 66:18-33

Howell EC, Barker GC, Jones GH et al (2002) Integration of the cytogenetic and genetic linkage maps of Brassica oleracea. Genetics 161:1225-1234

Howell EC, Armstrong SJ, Barker GC et al (2005) Physical organization of the major duplication on Brassica oleracea chromosome $\mathrm{O} 6$ revealed through fluorescence hybridization with Arabidopsis and Brassica BAC probes. Genome 48: 1093-1103

Hřibová E, Doleželová M, Doležel J (2008) Localization of BAC clones on mitotic chromosomes of Musa acuminata using fluorescence in situ hybridization. Biol Plant 52:445-452
Idziak D, Betekhtin A, Wolny E et al (2011) Painting the chromosomes of Brachypodium: current status and future prospects. Chromosoma 120:469-479

Iovene M, Grzebelus E, Carputo D, Jiang J, Simon PW (2008) Major cytogenetic landmarks and karyotype analysis in Daucus carota and other Apiaceae. Am J Bot 95:793-804

Islam-Faridi MN, Childs KL, Klein PE et al (2002) A molecular cytogenetic map of sorghum chromosome 1. Fluorescence in situ hybridization analysis with mapped bacterial artificial chromosomes. Genetics 161:345-353

Iwata A, Greenland CM, Jackson SA (2013) Cytogenetics of legumes in the phaseoloid clade. Plant Genome 6(3)

Jenkins G, Hasterok R (2007) BAC 'landing' on chromosomes of Brachypodium distachyon for comparative genome alignment. Nat Protoc 2:88-98

Jiang J, Gill BS, Wang GL, Ronald PC, Ward DC (1995) Metaphase and interphase fluorescence in situ hybridization mapping of the rice genome with bacterial artificial chromosomes. Proc Natl Acad Sci U S A 92:4487-4491

Jiang J, Birchler JA, Parrott WA, Dawe RK (2003) A molecular view of plant centromeres. Trends Plant Sci 8:570-575

Kaczmarek A, Naganowska B, Wolko B (2009) Karyotyping of the narrow-leafed lupin (Lupinus angustifolius L.) by using FISH, PRINS and computer measurements of chromosomes. J Appl Genet 50:77-82

Kamphuis LG, Hane JK, Nelson MN, Gao L, Atkins CA, Singh KB (2015) Transcriptome sequencing of different narrowleafed lupin tissue types provides a comprehensive uni-gene assembly and extensive gene-based molecular markers. Plant Biotechnol J 13:14-25

Kang YJ, Kim SK, Kim MY et al (2014) Genome sequence of mungbean and insights into evolution within Vigna species. Nat Commun 5:5443

Kasprzak A, Safar J, Janda J, Dolezel J, Wolko B, Naganowska B (2006) The bacterial artificial chromosome (BAC) library of the narrow-leafed lupin (Lupinus angustifolius L.). Cell Mol Biol Lett 11:396-407

Kato A, Vega JM, Han F, Lamb JC, Birchler JA (2005) Advances in plant chromosome identification and cytogenetic techniques. Curr Opin Plant Biol 8:148-154

Kaufmann S, Frishman D (2014) Analysis of microrearrangements in 25 eukaryotic species pairs by SyntenyMapper. PLoS ONE 9(11):e112341

Kim JS, Childs KL, Islam-Faridi MN et al (2002) Integrated karyotyping of sorghum by in situ hybridization of landed BACs. Genome 45:402-412

Kohany O, Gentles AJ, Hankus L, Jurka J (2006) Annotation, submission and screening of repetitive elements in Repbase: RepbaseSubmitter and Censor. BMC Bioinformatics 7:474

Konieczny A, Ausubel FM (1993) A procedure for mapping Arabidopsis mutations using co-dominant ecotype-specific PCR-based markers. Plant J 4:403-410

Koo DH, Jo SH, Bang JW, Park HM, Lee S, Choi D (2008) Integration of cytogenetic and genetic linkage maps unveils the physical architecture of tomato chromosome 2. Genetics 179:1211-1220

Koornneef M, Fransz P, de Jong H (2003) Cytogenetic tools for Arabidopsis thaliana. Chromosome Res 11:183-194

Krishnan P, Sapra VT, Soliman KM, Zipf A (2001) FISH mapping of the $5 \mathrm{~S}$ and $18 \mathrm{~S}-28 \mathrm{~S}$ rDNA loci in different species of Glycine. J Hered 92:295-300 
Kroc M, Koczyk G, Swiecicki W, Kilian A, Nelson MN (2014) New evidence of ancestral polyploidy in the Genistoid legume Lupinus angustifolius L. (narrow-leafed lupin). Theor Appl Genet 127:1237-1249

Krzywinski M, Schein J, Birol I, Connors J, Gascoyne R, Horsman D, Jones SJ, Marra MA (2009) Circos: an information aesthetic for comparative genomics. Genome Res 19: 1639-1645

Książkiewicz M, Wyrwa K, Szczepaniak A et al (2013) Comparative genomics of Lupinus angustifolius gene-rich regions: BAC library exploration, genetic mapping and cytogenetics. BMC Genomics 14:79

Książkiewicz M, Zielezinski A, Wyrwa K et al (2015) Remnants of the legume ancestral genome preserved in gene-rich regions: insights from physical, genetic, and comparative mapping. Plant Mol Biol Report 33:84-101

Kulikova O, Geurts R, Lamine M et al (2004) Satellite repeats in the functional centromere and pericentromeric heterochromatin of Medicago truncatula. Chromosoma 113:276-283

Kwiatek M, Wisniewska H, Apolinarska B (2013) Cytogenetic analysis of Aegilops chromosomes, potentially usable in triticale (X Triticosecale Witt.) breeding. J Appl Genet 54:147-155

Lamb JC, Danilova T, Bauer MJ et al (2007) Single-gene detection and karyotyping using small-target fluorescence in situ hybridization on maize somatic chromosomes. Genetics 175 : 1047-1058

Leśniewska K, Książkiewicz M, Nelson MN et al (2011) Assignment of 3 genetic linkage groups to 3 chromosomes of narrow-leafed lupin. J Hered 102:228-236

Lewis G, Schrire B, Mackind B, Lock M (2005) Legumes of the world. Royal Botanic Gardens, Kew

Lin JY, Stupar RM, Hans C, Hyten DL, Jackson SA (2010) Structural and functional divergence of a $1-\mathrm{Mb}$ duplicated region in the soybean (Glycine max) genome and comparison to an orthologous region from Phaseolus vulgaris. Plant Cell 22:2545-2561

Lyons E, Pedersen B, Kane J et al (2008) Finding and comparing syntenic regions among Arabidopsis and the outgroups papaya, poplar, and grape: CoGe with rosids. Plant Physiol 148: 1772-1781

Lysak MA, Fransz PF, Ali HB, Schubert I (2001) Chromosome painting in Arabidopsis thaliana. Plant J 28:689-697

Ma J, Wing RA, Bennetzen JL, Jackson SA (2007a) Evolutionary history and positional shift of a rice centromere. Genetics 177:1217-1220

Ma J, Wing RA, Bennetzen JL, Jackson SA (2007b) Plant centromere organization: a dynamic structure with conserved functions. Trends Genet 23:134-139

Macknight RC, Reynolds PH, Farnden KJ (1995) Analysis of the lupin Nodulin-45 promoter: conserved regulatory sequences are important for promoter activity. Plant Mol Biol 27:457-466

McClean PE, Mamidi S, McConnell M, Chikara S, Lee R (2010) Synteny mapping between common bean and soybean reveals extensive blocks of shared loci. BMC Genomics 11:184

Melters DP, Bradnam KR, Young HA et al (2013) Comparative analysis of tandem repeats from hundreds of species reveals unique insights into centromere evolution. Genome Biol 14:R10

Naganowska B, Zielinska A (2002) Physical mapping of 18S-25S rDNA and 5S rDNA in Lupinus via fluorescent in situ hybridization. Cell Mol Biol Lett 7:665-670
Naganowska B, Zielinska A (2004) Localisation of rDNA in the Lupinus genome during the cell cycle. J Appl Genet 45:189-193

Naganowska B, Wolko B, Sliwinska E, Kaczmarek Z (2003) Nuclear DNA content variation and species relationships in the genus Lupinus (Fabaceae). Ann Bot 92:349-355

Narożna D (2014) Analiza fragmentów genomu łubinu wąskolistnego (Lupinus angustifolius L.) zawierających sekwencje kodujące syntezę chalkonową. Poznań University of Life Sciences

Neff MM, Neff JD, Chory J, Pepper AE (1998) dCAPS, a simple technique for the genetic analysis of single nucleotide polymorphisms: experimental applications in Arabidopsis thaliana genetics. Plant J 14:387-392

Nelson MN, Phan HT, Ellwood SR et al (2006) The first genebased map of Lupinus angustifolius L.-location of domestication genes and conserved synteny with Medicago truncatula. Theor Appl Genet 113:225-238

Nelson MN, Moolhuijzen PM, Boersma JG et al (2010) Aligning a new reference genetic map of Lupinus angustifolius with the genome sequence of the model legume, Lotus japonicus. DNA Res 17:73-83

Neumann P, Pavlikova Z, Koblizkova A et al (2015) Centromeres off the hook: massive changes in centromere size and structure following duplication of $\mathrm{CenH} 3$ gene in Fabeae species. Mol Biol Evol 32:1862-1879

Ohmido N, Ishimaru A, Kato S, Sato S, Tabata S, Fukui K (2010) Integration of cytogenetic and genetic linkage maps of Lotus japonicus, a model plant for legumes. Chromosome Res 18: 287-299

Ouyang S, Buell RC (2004) The TIGR plant repeat databases: a collective resource for the identification of repetitive sequences in plants. Nucleic Acids Res 32(Database issue): D360-D363

Paterson AH, Bowers JE, Burow MD et al (2000) Comparative genomics of plant chromosomes. Plant Cell 12:1523-1540

Pedrosa-Harand A, Kami J, Gepts P, Geffroy V, Schweizer D (2009) Cytogenetic mapping of common bean chromosomes reveals a less compartmentalized small-genome plant species. Chromosome Res 17:405-417

Pfeil BE, Schlueter JA, Shoemaker RC, Doyle JJ (2005) Placing paleopolyploidy in relation to taxon divergence: a phylogenetic analysis in legumes using 39 gene families. Syst Biol 54:441-454

Przysiecka Ł, Ksiazkiewicz M, Wolko B, Naganowska B (2015) Structure, expression profile and phylogenetic inference of chalcone isomerase-like genes from the narrow-leafed lupin (Lupinus angustifolius L.) genome. Front Plant Sci 6:268

Reinprecht Y, Yadegari Z, Perry GE et al (2013) In silico comparison of genomic regions containing genes coding for enzymes and transcription factors for the phenylpropanoid pathway in Phaseolus vulgaris L. and Glycine max L. Merr. Front Plant Sci 4:317

Ren Y, Zhao H, Kou Q et al (2012) A high resolution genetic map anchoring scaffolds of the sequenced watermelon genome. PLoS ONE 7:e29453

Revanna KV, Chiu CC, Bierschank E, Dong Q (2011) GSV: a web-based genome synteny viewer for customized data. BMC Bioinformatics 12:316

Salamov AA, Solovyev VV (2000) Ab initio gene finding in Drosophila genomic DNA. Genome Res 10:516-522 
Sato S, Nakamura Y, Asamizu E, Isobe S, Tabata S (2007) Genome sequencing and genome resources in model legumes. Plant Physiol 144:588-593

Sato S, Nakamura Y, Kaneko T et al (2008) Genome structure of the legume, Lotus japonicus. DNA Res 15:227-239

Schlueter JA, Dixon P, Granger C et al (2004) Mining EST databases to resolve evolutionary events in major crop species. Genome 47:868-876

Schmutz J, Cannon SB, Schlueter J et al (2010) Genome sequence of the palaeopolyploid soybean. Nature 463:178-183

Schmutz J, McClean PE, Mamidi S et al (2014) A reference genome for common bean and genome-wide analysis of dual domestications. Nat Genet 46:707-713

Schnabel E, Kulikova O, Penmetsa RV, Bisseling T, Cook DR, Frugoli J (2003) An integrated physical, genetic and cytogenetic map around the sunn locus of Medicago truncatula. Genome 46:665-672

Schuller KA, Turpin DH, Plaxton WC (1990) Metabolite regulation of partially purified soybean nodule phosphoenolpyruvate carboxylase. Plant Physiol 94:1429-1435

Seijo JG, Lavia GI, Fernandez A, Krapovickas A, Ducasse D, Moscone EA (2004) Physical mapping of the 5S and 18S25S rRNA genes by FISH as evidence that Arachis duranensis and $A$. ipaensis are the wild diploid progenitors of A. hypogaea (Leguminosae). Am J Bot 91:1294-1303

Sharma SK, Bolser D, de Boer J et al (2013) Construction of reference chromosome-scale pseudomolecules for potato: integrating the potato genome with genetic and physical maps. G3 (Bethesda) 3:2031-2047

Shearer LA, Anderson LK, de Jong H et al (2014) Fluorescence in situ hybridization and optical mapping to correct scaffold arrangement in the tomato genome. G3 (Bethesda) 4:13951405

Sobreira NL, Gnanakkan V, Walsh M et al (2011) Characterization of complex chromosomal rearrangements by targeted capture and next-generation sequencing. Genome Res 21:1720-1727

Spannagl M, Noubibou O, Haase D et al (2007) MIPSPlantsDBplant database resource for integrative and comparative plant genome research. Nucleic Acids Res 35:D834-D840
Sun J, Zhang Z, Zong X, Huang S, Li Z, Han Y (2013) A highresolution cucumber cytogenetic map integrated with the genome assembly. BMC Genomics 14:461

Tek AL, Kashihara K, Murata M, Nagaki K (2010) Functional centromeres in soybean include two distinct tandem repeats and a retrotransposon. Chromosome Res 18:337-347

Unfried I, Gruendler P (1990) Nucleotide sequence of the 5.8S and 25S rRNA genes and of the internal transcribed spacers from Arabidopsis thaliana. Nucleic Acids Res 18:4011

Untergasser A, Nijveen H, Rao X, Bisseling T, Geurts R, Leunissen JA (2007) Primer3Plus, an enhanced web interface to Primer3. Nucleic Acids Res 35:W71-W74

Varshney RK, Chen W, Li Y et al (2012) Draft genome sequence of pigeonpea (Cajanus cajan), an orphan legume crop of resource-poor farmers. Nat Biotechnol 30:83-89

Varshney RK, Song C, Saxena RK et al (2013) Draft genome sequence of chickpea (Cicer arietinum) provides a resource for trait improvement. Nat Biotechnol 31:240-246

Voorrips RE (2002) MapChart: software for the graphical presentation of linkage maps and QTLs. J Hered 93:77-78

Wallace IS, Choi WG, Roberts DM (2006) The structure, function and regulation of the nodulin 26-like intrinsic protein family of plant aquaglyceroporins. Biochim Biophys Acta 1758:1165-1175

Yang H, Tao Y, Zheng Z et al (2013) Draft genome sequence, and a sequence-defined genetic linkage map of the legume crop species Lupinus angustifolius L. PLoS ONE 8:e64799

Yang H, Jian J, Li X, Renshaw D, Clements J, Sweetingham MW, Tan C, Li C (2015) Application of whole genome resequencing data in the development of diagnostic DNA markers tightly linked to a disease-resistance locus for marker-assisted selection in lupin (Lupinus angustifolius). BMC Genomics 16:660

Yi C, Zhang W, Dai X et al (2013) Identification and diversity of functional centromere satellites in the wild rice species Oryza brachyantha. Chromosome Res 21:725-737

Young ND, Debelle F, Oldroyd GE et al (2011) The Medicago genome provides insight into the evolution of rhizobial symbioses. Nature 480:520-524

Young HA, Sarath G, Tobias CM (2012) Karyotype variation is indicative of subgenomic and ecotypic differentiation in switchgrass. BMC Plant Biol 12:117 